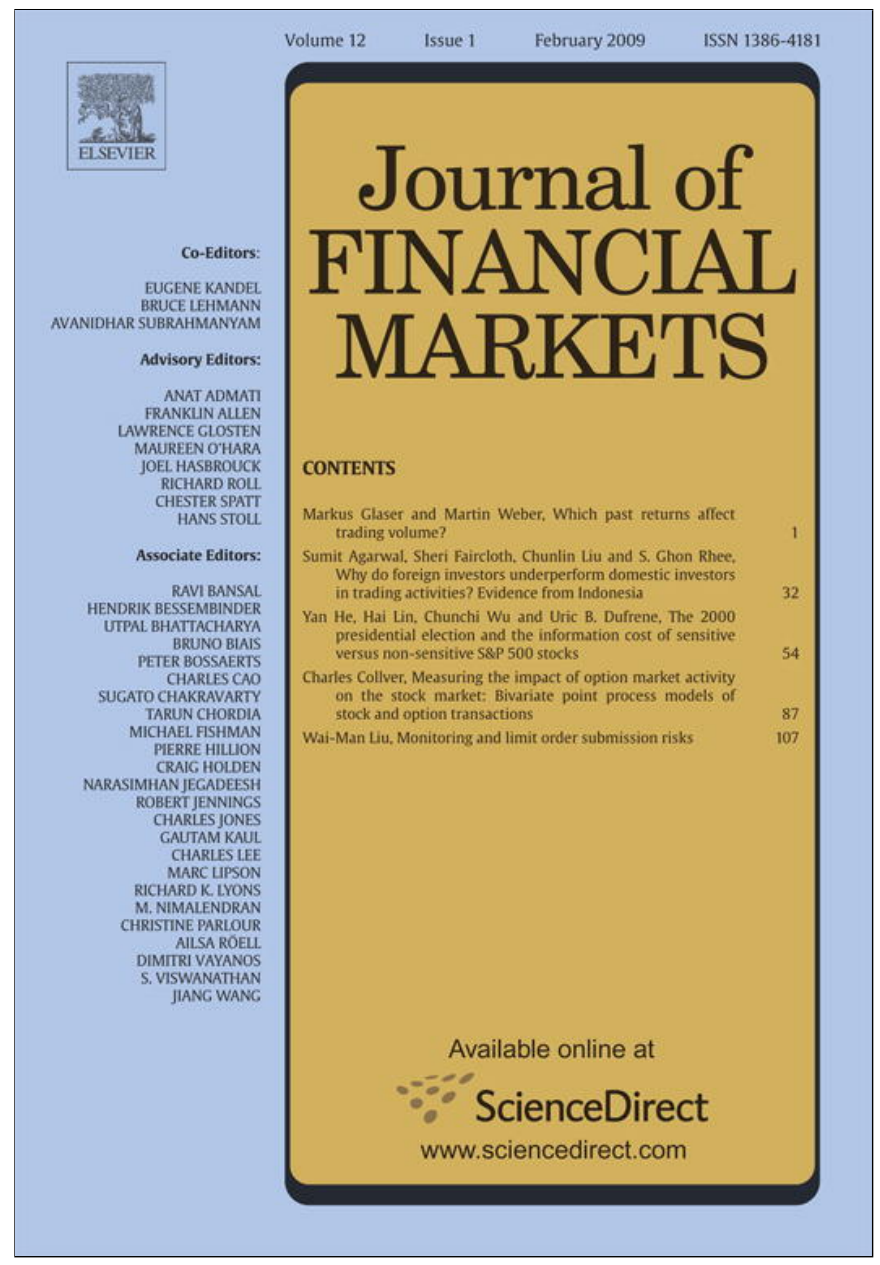

This article appeared in a journal published by Elsevier. The attached copy is furnished to the author for internal non-commercial research and education use, including for instruction at the authors institution and sharing with colleagues.

Other uses, including reproduction and distribution, or selling or licensing copies, or posting to personal, institutional or third party websites are prohibited.

In most cases authors are permitted to post their version of the article (e.g. in Word or Tex form) to their personal website or institutional repository. Authors requiring further information regarding Elsevier's archiving and manuscript policies are encouraged to visit:

http://www.elsevier.com/copyright 


\title{
Monitoring and limit order submission risks ${ }^{\text {is }}$
}

\author{
Wai-Man Liu* \\ School of Banking and Finance, University of New South Wales, Sydney, NSW 2052, Australia
}

Available online 7 May 2008

\begin{abstract}
This paper presents a formal analysis of the relation between monitoring and limit order submission risk. With heterogeneous information, limit order traders face two types of risk. First, they may be "picked off" when prices change unexpectedly after the limit order is entered (known as free trading option risk). Second, they face the possibility that their limit order will not result in a trade. To mitigate these risks, traders can monitor information and prices and cancel or revise their orders as needed. But such monitoring is costly, resulting in a trade-off between the cost of monitoring and the risks of limit order submission. The model predicts that if the stock is actively traded, limit order submission risks and order cancellations/revisions are positively related. Further, shares with a wide bid-ask spread will tend to have a lower rate of order cancellations and revisions than shares with small bid-ask spreads. Finally, the model suggests that if larger capitalization stocks have lower costs of gathering information (and hence more intense monitoring of limit orders), there will be more cancellations and revisions in limit orders. A sample of 23 liquid stocks provides evidence that is consistent with these three main hypotheses.

(C) 2008 Elsevier B.V. All rights reserved.
\end{abstract}

JEL classification: F10; G14

Keywords: Limit orders; Free trading option; Non-execution risk; News monitoring

\footnotetext{
This paper is based on my Ph.D. thesis at the University of Melbourne. I am indebted to my supervisors, Rob Brown and Kim Sawyer. Their comprehensive comments and constant inspirations on the topic have been invaluable. I acknowledge helpful discussions and comments made by an anonymous referee, Henk Berkman, Doug Foster, Larry Harris, Rob Neal, Marios Panayides, Christine Parlour, Patrik Sandås, Avanidhar Subrahmanyam (editor), Terry Walter, Jian-Xin Wang, Steven Wei, George Wong, faculty members of the University of Melbourne, seminar and workshop participants at the Chinese University of Hong Kong, Hong Kong Polytechnic University, University of New South Wales, the 6th Annual Melbourne-Monash Ph.D. Symposium, 2005 FMA Conference held in Chicago and the 12th SFM Conference held in the National Sun Yat-sen University, Taiwan. Especially, I thank Paul Francis for his enormous help in data extraction and his generosity in sharing a program that reconstructs the limit order book from the original SIRCA order flow data. I am responsible for any errors.

*Tel.: + 61293855852 ; fax: + 61293856347.

E-mail address: wmr.liu@unsw.edu.au
} 
In practice, limit order traders cannot instantaneously reprice their orders exactly when repricing would be optimal. The costs of paying attention ensure that values may change substantially before they notice the change. Harris (2003, p. 307)

\section{Introduction}

Recent research has documented a striking number of limit order cancellations in microstructure data. Ellul, Holden, Jain, and Jennings (2007) and Yeo (2005) report that more than one-third of all order submissions on the NYSE are cancelled before they are executed. Recent observation suggests that as many as $70 \%$ of limit orders on the NYSE are cancelled. ${ }^{1}$ Hasbrouck and Saar (2002) observe that more than a quarter of all visible orders submitted to Island ECN are cancelled within two seconds of their submission. They attribute this phenomenon to the order routing system provided by the brokers and ECNs when market participants are actively searching for the best price among different market centers. In the futures market, it appears that the frequency of limit order cancellation is even higher. Coppejans and Domowitz (2002) report that the daily average number of limit order cancellations on stock index futures contracts traded on the London Securities and Derivatives Exchange exceeds $60 \%$ of the total order flow. A convenient explanation of this overall high level of cancellation activity is the recent advancement in information technology and the growing number of electronic trading venues that allow traders to cancel and revise directly from their desktop computers. But this explanation does not offer an answer as to why traders cancel their orders.

To understand the motive behind order cancellation, we must better understand the risks inherent in limit order placement. In principle, there are two types of risk which limit order traders face when unexpected information arrives. First, if the information is "good (bad) news" it will drive the value of the asset above (below) the current market price. Hence, limit sell (buy) orders are susceptible to being picked off or traded at too low (high) a price relative to the news. This risk is commonly referred to as "free trading option" (FTO hereafter) risk, since a limit sell (buy) order is equivalent to writing a conditional free call (put) option..$^{2}$ The value of the option is conditional on the arrival of public information. ${ }^{3}$ Second, traders face the risk of non-execution: that is, an order may not be filled to meet the trader's preferred schedule, which may be due to their willingness to invest or disinvest the cash flows. Non-execution risk arises when the market price moves away from the limit price. The outcome is that traders suffer an opportunity cost as they must execute

\footnotetext{
${ }^{1}$ I thank Li Wei from the NYSE for providing this information.

${ }^{2}$ Free option problem has been described in a number of studies, among them Copeland and Galai (1983), Stoll (1992), Angel (1994), Berkman (1996), Handa and Schwartz (1996), Foucault (1999), Sandås (2001), Foucault, Röell, and Sandås (2003). Liu and Sawyer (2003) formalize this problem in an information rich environment when limit orders are not promptly withdrawn. In most limit order books, the free trading options are not exercised either because they are out-of-the-money (no price reversal) or because the limit order is cancelled on the arrival of information that is adverse to the limit price.

${ }^{3}$ Readers should not confuse free trading option risk with adverse selection risk. In the presence of adverse selection risk, limit orders do not have a positive option value because they have an infinitesimally small maturity (Stoll, 1992). An informed trader with private information will pick off limit orders immediately after they are entered. A much clearer distinction between the two is provided in Stoll (2003). Stoll asserts that free trading option risk arises because of the arrival of adverse public information before the trade, while adverse selection risk arises because of the presence of private information before the trade, which is revealed some time after the trade.
} 
transactions on inferior terms. To reduce this opportunity cost, traders can pick off stale orders on the opposite side of the book before those orders are revised/withdrawn. Therefore, the risk of non-execution can be regarded as the counter to FTO risk. ${ }^{4}$

There are two ways to mitigate these risks. First, patient traders can reduce the risk of being picked off by widening the limit order spread: the difference between the limit sell (buy) price submitted and the best bid (offer) price. The disadvantage of this strategy is that it reduces the chance of the order's being filled by liquidity traders who have no information motive. Second, patient traders can monitor public news, so that they can withdraw orders if the FTO value becomes in-the-money. To reduce the cost of nonexecution when their bid (ask) is too low (high), they revise their quotes and attempt to pick off a prevailing market ask (bid) before the quote is withdrawn or revised. Such a strategy is costly, so patient traders must balance the cost of monitoring against the expected costs of FTO risk and non-execution risk. If the cost of monitoring is reasonably low, traders will watch the information flow closely, post small spreads to attract uninformed investors, and swiftly cancel/revise their orders when circumstances change. This means that limit order traders create two benefits from monitoring news: lowering the expected FTO cost embedded in the limit order and decreasing the expected cost of nonexecution if news drives the value of the asset away from the limit order.

To understand these issues more clearly, I provide a simple model to derive relations between spread, limit order cancellation/revision and limit order submission risks. The model analyzes three risk-neutral agents over three periods. There is a patient buyer, a patient seller and a newswatcher. In the initial stage of the game, each agent chooses a probability that he/she acquires the information and reacts before others, prior to the release of price-sensitive news. In the second stage, patient traders post competitive bid and ask quotes to the limit order book. In the final stage, information is released and is revealed to traders according to the probabilities they have chosen. This information may change the value of the asset, and therefore limit orders posted by patient traders may become obsolete. Only one of the three traders receives information before the others. If either the patient buyer or the patient seller receives the information first, and discovers that their order is in-the-money, they will withdraw or revise the order to avoid being picked off. If the market price moves away from the order of the patient buyer or patient seller, they will convert their limit order to a market order and immediately fill the contraside quote, thereby reducing the cost of non-execution. If the newswatcher receives this information before patient traders, he/she will profit from picking off overpriced bid or underpriced ask. I demonstrate that in equilibrium, there exists a positive relation between limit order submission risks and order cancellation or revision activity. I also show that when the spread is wide and when firm size is small, cancellation or revision activity is predicted to be low.

These predictions are tested with a unique dataset of order flow activity taken from 23 actively traded stocks on the Australian Stock Exchange. I use data from the year 1999 and I divide each trading day into seven one-hour intervals. For each interval I record the

\footnotetext{
${ }^{4}$ A survey of institutional trading practices done by Economides and Schwartz (1995) reveals that two-thirds of their respondents frequently use limit orders to trade. While these respondents are professional investors (who tend to observe the market quite closely and typically have low monitoring costs), a majority of them consider the risk of non-execution as the most important drawback and the risk of adverse execution as the second drawback of using limit orders.
} 
number of order cancellations and revisions, all transactions, the average bid-ask spread and the average market depth. I also compute free option values for each interval to proxy for both FTO risk and non-execution risk. The evidence is consistent with traders who monitor their orders to avoid both being picked off and to reduce the risk of nonexecution. When FTO risk is high, limit buyers are less capable of withdrawing their orders promptly, as sellers maneuver more quickly than buyers and pick off any orders not amended. Also, traders are more likely to withdraw their orders than to revise them, possibly because of the subsequent high monitoring cost associated with a revised order, evidence that supports the dynamic order submission model of Harris (1998). In addition, there is a significant increase in price revisions when limit orders are exposed to high nonexecution risk from temporary price changes. I find weak evidence of a negative and significant relation between the number of order cancellations/revisions and the average bid-ask spread, which suggests that traders widen the spread when they choose not to monitor. A positive relation between order cancellation/revision counts and firm size is consistent with greater levels of press and analyst coverage of large stocks encouraging more traders to monitor information flows, ready to cancel/revise if limit orders become mispriced. These results add to the existing evidence on order cancellation, which has focused largely on cancellations and non-execution risk (Griffiths, Smith, Turnbull, and White, 2000; Coppejans and Domowitz, 2002; Ranaldo, 2004; Ellul, Holden, Jain, and Jennings, 2007) as well as noting a U-shaped intraday pattern in cancellations (Biais, Hillion, and Spatt, 1995; Coppejans and Domowitz, 2002; Ellul, Holden, Jain, and Jennings, 2007). This paper provides new evidence on the association between FTO risk and order cancellation and analyzes order revisions.

While there is considerable extant literature examining options values inherent in quotes, the importance of order cancellation and revision as part of order placement strategy has been overlooked. Copeland and Galai (1983) characterize a dealer's quote submission as writing a free straddle option to a potentially informed trader, if they have an obligation to post two-sided quotes and cannot withdraw their quotes. Therefore the quotes include option values based on the assumption that they are not revised within a given interval. Angel's (1994) model of order execution probability assumes that limit orders cannot be canceled once submitted. Parlour's (1998) dynamic equilibrium model assumes that there is no FTO risk, which implies that order withdrawal has no value as patient traders lose their time-priority if they withdraw and resubmit their orders. Foucault (1999) models the relation between FTO risk and order submission. In his model, patient traders widen the spread in anticipation of the arrival of adverse news; monitoring and order cancellation/ revision play no role in the trader's decision. Glosten (1994) derives an equilibrium model of the limit order book. Despite the assumption of no order withdrawal or revision in the face of adverse information risk, he acknowledges that limit order placement is not costless "since it requires some monitoring to ensure that orders are not left exposed, for example, after a public information release" (pp. 1151-1152). To reduce FTO risk, Brown and Holden (2002) suggest an alternative design for a limit order. They call it the "adjustable limit order", which automatically updates the price in response to market index changes or dealers' quote changes. They assume that a regular limit order submitter does not monitor and so orders are not withdrawn or revised when information arrives. Harris (1998) develops a dynamic limit order submission model that explicitly considers the option to revise. While he underscores the significance of order revision, the model does not establish a link between the value of FTOs, non-execution cost, monitoring intensity and limit prices 
because the decision to monitor is not endogenized. More recent models of order placement, such as Goettler, Parlour, and Rajan (2005), recognize the importance of order cancellation and model the order cancellation probability as a function of the evolution of the asset's common value.

The model presented in this paper is closely related to Foucault, Röell, and Sandås (2003), who focus explicitly on the spread-monitoring relation and develop a model that endogenizes monitoring intensity by dealers on the NASDAQ to avoid being picked off by SOES bandits. These bandits are speculators who closely monitor the market to pick off stale quotes posted by dealers. In response, dealers monitor (i) news arrival and (ii) the quotes of other dealers. In Foucault et al.'s model, dealers cannot pick off other dealers and do not suffer non-execution risk. The model developed below is the first to formalize and derive testable implications for the relation between monitoring, order cancellation/ revision and the bid-ask spread.

The remainder of the paper is organized as follows. Section 2 presents a simple model and discusses various testable implications. Sections 3 and 4 discuss the empirical methodology and the dataset. The empirical results are reported and discussed in Section 5. I conclude in Section 6.

\section{A simple model}

Consider a simple trading game played by three categories of risk-neutral agents trading a single asset. The traders' roles are as follows: (i) a patient seller (denoted by $s$ ), (ii) a patient buyer (denoted by $b$ ) and (iii) a newswatcher (denoted by $n$ ).

Define $V_{0}$ to be the expected liquidation value of this asset at time 0 . Over time the value of the asset evolves as follows. A piece of news is released at time 1 (final stage of the trading game); with probability $\alpha$, there is an innovation in the asset value. The final liquidation value, $V_{1}$, may increase to $V_{0}+\sigma$ or decrease to $V_{0}-\sigma$, with equal probabilities of $\alpha / 2$ each. With probability $1-\alpha$, there is no innovation in the asset value.

At time 0, both patient traders and the newswatcher arrive at the market simultaneously. Each trader chooses a probability that represents the likelihood that he/she will acquire the news and react before the others. I label this probability $\lambda_{m}, \forall m=b, s, n$. Whoever acquires the news will react to the news immediately and then the game ends. While only one player will receive the news ahead of the others (subsequent to its release at time 1), nature reveals the news to players according to their chosen probabilities. ${ }^{5}$ In addition, the patient buyer and seller choose prices for their bid quote and ask quote respectively. For tractability it is assumed that both quotes are valid for a single unit of the asset.

In this trading game, the patient trader and newswatcher compete to be the first to acquire and react to new information about the value of the asset. The game consists of three stages.

Stage 1 (Monitoring stage): Each player simultaneously chooses the probability $\lambda_{m}$, $\forall m=b, s, n$ and $\sum \lambda_{m} \leqslant 1$. Given the ask quote $\left(A_{0}\right)$ and the bid quote $\left(B_{0}\right), \lambda_{m}$ is chosen by trading off the costs and benefits of monitoring. For patient seller $s$ and patient buyer $b$,

\footnotetext{
${ }^{5}$ This monitoring game could be thought of as a queuing game; each player chooses a probability of joining the queue with only one player being the first in the line. Thus, $\lambda_{m}$ can be thought of as the odds on a four-sided dice which is rolled once (since the sum of $\lambda_{m}$ need not be unity) and only one trader acquires and reacts to news before the other two traders.
} 
the benefits are the free option cost saved and the non-execution cost saved should they acquire the information first. Free option cost is saved when seller $s$ (buyer $b$ ) withdraw his ask (bid) quote before being picked off when the asset value rises (falls). Non-execution cost is saved when seller $s$ (buyer $b$ ) withdraws his quote and picks off the unadjusted contra-side bid (ask) quote before the bid (ask) quote is cancelled by patient buyer $b$ (seller $s$ ) or picked off by newswatcher $n$. For the newswatcher, the benefits are the free options exercised in picking off the mispriced bid and ask quotes:

$$
\begin{aligned}
& \text { Patient seller } s: \max _{\lambda s} \underbrace{\frac{\alpha}{2} \lambda_{s}\left(\sigma-\left(A_{0}-V_{0}\right)\right)}_{\text {FTO cost saved }}+\underbrace{\frac{\alpha}{2} \lambda_{s}\left(\sigma-\left(V_{0}-B_{0}\right)\right)}_{\text {non-execution cost saved }}-c \lambda_{s}^{2} \\
& \text { Patient buyer } b: \max _{\lambda_{b}} \underbrace{\frac{\alpha}{2} \lambda_{b}\left(\sigma-\left(V_{0}-B_{0}\right)\right)}_{\text {FTO cost saved }}+\underbrace{\frac{\alpha}{2} \lambda_{b}\left(\sigma-\left(A_{0}-V_{0}\right)\right)}_{\text {non-execution cost saved }}-c \lambda_{b}^{2} \\
& \text { Newswatcher } n: \max _{\lambda_{n}} \underbrace{\frac{\alpha}{2} \lambda_{n}\left(\sigma-\left(A_{0}-V_{0}\right)\right)}_{\text {FTO of an underpriced ask }}+\underbrace{\frac{\alpha}{2} \lambda_{n}\left(\sigma-\left(V_{0}-B_{0}\right)\right)}_{\text {FTO of an overpriced bid }}-c \lambda_{n}^{2} .
\end{aligned}
$$

I assume the cost of acquiring the information is $c \lambda_{m}^{2}$, where $c$ is a positive constant. It relates to the explicit cost associated with subscription to news services such as Bloomburg or Reuters, or it relates to the opportunity cost associated with the level of disutility caused by the effort exerted to monitor for new information; for example, traders may need to spend time to understand and filter the noisy signal inherent in accounting numbers when an earnings report is released.

Stage 2 (Quote setting): Patient traders set the bid quote and the ask quote and receive the following payoffs:

$$
\begin{aligned}
\Pi_{s}= & -\underbrace{\frac{\alpha}{2}\left(\lambda_{b}+\lambda_{n}\right)\left(\sigma-\left(A_{0}-V_{0}\right)\right)}_{\text {FTO cost }}-\underbrace{\frac{\alpha}{2}\left(\lambda_{b}+\lambda_{n}\right)\left(\sigma-\left(V_{0}-B_{0}\right)\right)}_{\text {Non-execution cost }} \\
& +\underbrace{(1-\alpha) \frac{\beta}{2}\left(A_{0}-V_{0}\right)}_{\begin{array}{c}
\text { Gain from trading against } \\
\text { the liquidity trader }
\end{array}}-c \lambda_{s}^{2} \\
\Pi_{b}= & -\underbrace{\frac{\alpha}{2}\left(\lambda_{s}+\lambda_{n}\right)\left(\sigma-\left(V_{0}-B_{0}\right)\right)}_{\text {FTO cost }}-\underbrace{\frac{\alpha}{2}\left(\lambda_{s}+\lambda_{n}\right)\left(\sigma-\left(A_{0}-V_{0}\right)\right)}_{\text {Non-execution cost }} \\
& +\underbrace{(1-\alpha) \frac{\beta}{2}\left(V_{0}-B_{0}\right)}_{\text {Gain from trading against }}-c \lambda_{b}^{2}
\end{aligned}
$$

The first term from the right hand side of Eq. (1a) represents the expected cost of being picked off faced by seller $s$ when $V_{1}=V_{0}+\sigma$. The probability of being picked off is given by the sum of probabilities that buyer $b$ and newswatcher $n$ acquire the information first: $\lambda_{b}+\lambda_{n}$. The second term from the right hand side of Eq. (1a) represents the expected cost 
of non-execution. The third term from the right hand side of Eq. (1a) captures the expected gain from trading against the liquidity trader.

Stage 3 (Information revelation stage): In the final stage, a piece of price-sensitive news is released. Nature chooses the news type. The innovation in the asset value is revealed to the trader according to the probabilities $\lambda_{m}$ chosen by traders. If there is no news, an uninformed liquidity buyer or liquidity seller arrives in the market with equal probability $\beta / 2$. If no liquidity trader arrives in the market, patient traders will match their orders at the expected liquidating value $V_{0}$ at the end of the trading game, since $V_{1}=V_{0}$.

As noted earlier, I assume the order size for every order submission is for only one unit. This assumption simplifies the analysis substantially, because traders do not need to consider the price impact of their trades when they submit their orders. In addition, I assume prices are continuous, which eliminates the consideration of time priority and the impact of tick size on monitoring and undercutting strategy. ${ }^{6}$ I also assume there are no other transaction costs of order placement or execution, except the cost of monitoring. Fig. 1 illustrates the timeline of the event.

\subsection{Equilibrium}

In this section, I present the equilibrium of the trading game. The equilibrium outcome comprises of a pair of competitive bid and ask quotes that is determined by (1) the optimal $\lambda_{m}$ chosen in Stage 1 and (2) the zero expected profit condition: $\Pi_{s}=\Pi_{b}=0$ in Stage 2 . Assuming that patient traders behave competitively and the bid-ask spread is set based on the condition that no one earns a strictly positive gain, patient traders expect others might arrive and undercut their orders. Bid and ask quotes are determined jointly through competitive forces: that is, $A_{0}$ and $B_{0}$ are set iteratively. The process of an iterative search for competitive prices resembles order submissions during the pre-opening phase in many markets. ${ }^{7}$ Note that for the zero expected profit condition to hold, the best ask price $A_{0}$ must be set lower than $V_{0}+\sigma$ and the best bid price $B_{0}$ must be set higher than $V_{0}-\sigma{ }^{8}$

Optimal solution from stage 1 yields ${ }^{9}$

$$
\lambda_{s}^{*}=\lambda_{b}^{*}=\lambda_{n}^{*}=\frac{\alpha}{4 c}\left(2 \sigma-S_{0}\right)
$$

where $S_{0} \equiv A_{0}-B_{0}$. The equilibrium spread with endogenous $\lambda_{m}^{*}, S_{0}^{*}$, is

$$
S_{0}^{*}=2 \sigma+\frac{2 c(1-\alpha) \beta}{5 \alpha^{2}}-\frac{8 c}{5 \alpha^{2}} \sqrt{(1-\alpha) \beta\left[(1-\alpha) \frac{\beta}{16}+\frac{5 \alpha^{2} \sigma}{8 c}\right]}
$$

\footnotetext{
${ }^{6}$ This issue is explored and analyzed in Cordella and Foucault's (1999) model of competitive bidding by two dealers.

${ }^{7}$ Markets such as the Paris Bourse, the Toronto Stock Exchange and the Australian Stock Exchange allow traders to submit orders to the system before the opening and traders can learn and revise their orders without any trade occurring.

${ }^{8}$ Let $B_{0}^{\prime}=V_{0}-\sigma$. Let $A_{0}^{\prime} \mid B_{0}^{\prime}$ be the ask price that is conditioned on $B_{0}^{\prime}$ and suppose the zero expected profit condition (1a) is satisfied. It can be shown that $\Pi_{j}\left(B_{0}^{\prime} \mid A_{0}^{\prime}\right)>0$, for all positive values of $\sigma, \alpha$ and $\beta$. A competitive buyer will undercut by posting a higher bid price so that it exceeds $B_{0}^{\prime}$. A similar argument applies for $A_{0}$.

${ }^{9}$ Second order conditions are satisfied.
} 


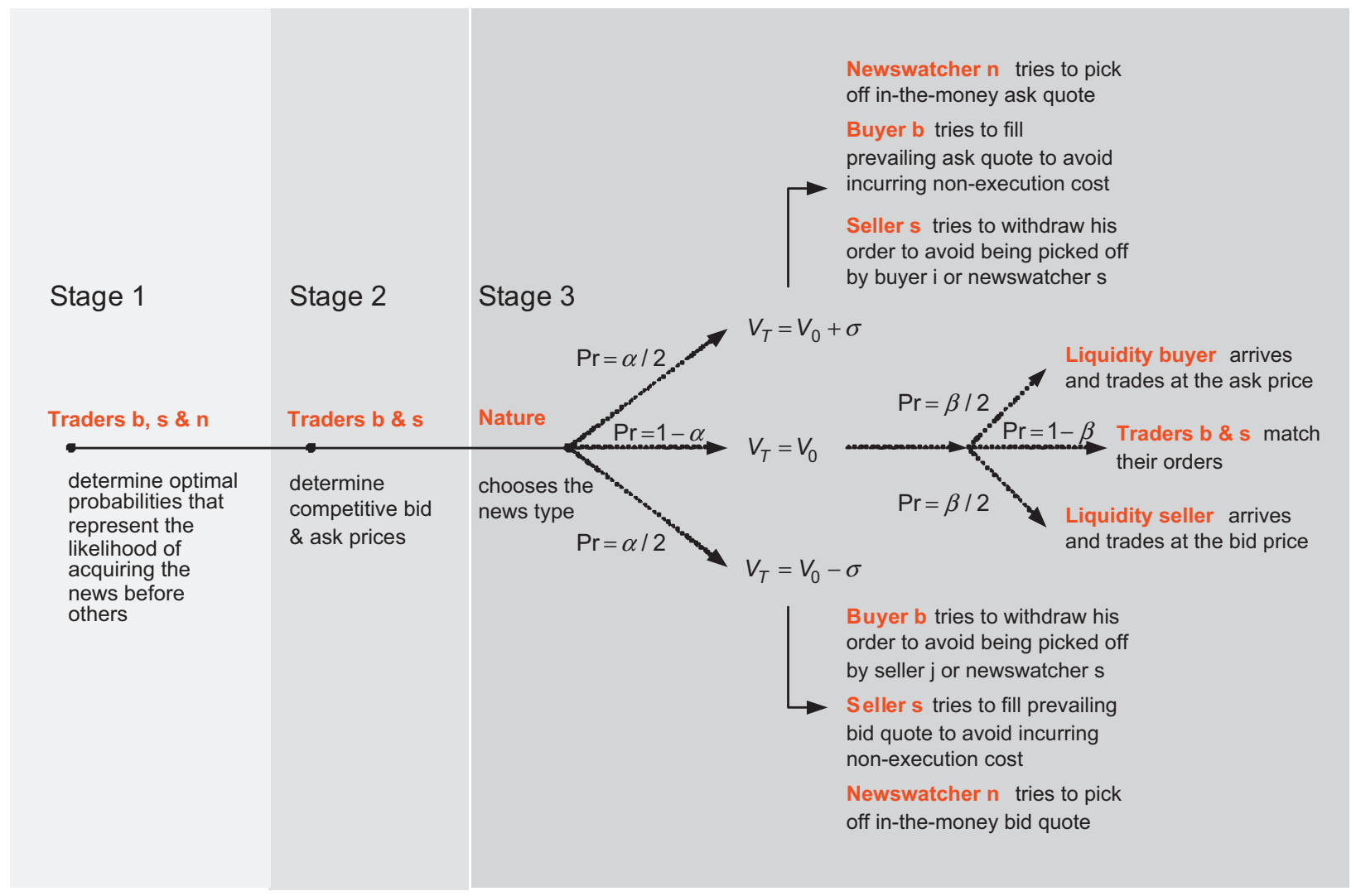

Fig. 1. Timeline of the event.

Substituting $S_{0}^{*}$ into Eq. (2) yields

$$
\lambda_{s}^{*}=\lambda_{b}^{*}=\lambda_{n}^{*}=\frac{(1-\alpha) \beta}{10 \alpha}\left[\sqrt{\left[1+\frac{10 \alpha^{2} \sigma}{(1-\alpha) \beta c}\right]}-1\right]
$$

\subsection{Testable hypotheses}

I now derive several testable hypotheses which highlight interrelations between order cancellation/revision, limit order submission risks and the bid-ask spread. The first proposition deals with the relation between limit order submission risks and the probability of successfully canceling or revising the order. Since $\lambda_{s}$ and $\lambda_{b}$ represent the probability of learning news before others, I assume that once the patient trader learns some news, he/she will immediately withdraw or revise his/her orders to mitigate the risk of being picked off or the risk of bearing non-execution cost. This implies that $\lambda_{s}$ and $\lambda_{b}$ are proportional to the rate of limit order cancellation and revision.

Proposition 1. If $\beta>\beta^{\prime} \equiv 5 \alpha^{2} / 3[1-\alpha(1-\alpha)]$, there is a positive relation between the rate of cancellation/revision and the cost of being picked off and a positive relation between the rate of cancellation/revision and the cost of non-execution.

Proof. See Appendix.

Actively traded stocks are more likely to satisfy the condition $\beta>\beta^{\prime}$ than inactively traded stocks, because they tend to have a higher probability of liquidity trading (higher $\beta$ ) 
than their counterpart. ${ }^{10}$ The logic behind Proposition 1 is fairly straightforward. If a stock is highly liquid, the equilibrium bid-ask spread is small. An increase in $\alpha$ raises the marginal benefit of news monitoring, as patient traders choose higher $\lambda_{s}$ and $\lambda_{b}$ instead of widening the spread to protect themselves against the risk of being picked off, and against the risk that the contra-side quotes move away from their quotes. If the stock is illiquid, an increase in $\alpha$ causes the traders to widen the spread further, as the low probability of uninformed traders' arrival implies that the gain of supplying liquidity is insufficient to compensate for its risk. As traders widen the spread, the marginal benefit of news monitoring is reduced and, in equilibrium, traders are less likely to arrive and cancel/revise their limit orders. Proposition 1 leads to the following testable hypotheses:

Hypothesis 1a (FTO risk). For liquidly traded stocks, the number of limit sell (buy) order cancellations and revisions increases when the value of free call (put) option increases.

Hypothesis 1b (Non-execution risk). For liquidly traded stocks, the number of limit sell (buy) order cancellations and revisions increases when the value of free put (call) option increases.

Empirically, $\lambda_{s}$ and $\lambda_{b}$ relate to the number of order cancellations/revisions in any interval of length $T$. Because of the dual nature of these two types of limit order submission risk, the expected cost of non-execution of seller $s$ 's (buyer b's) order is equivalent to the expected FTO cost of buyer $b$ 's (seller $s$ 's) order.

The second hypothesis deals with the negative relation between the bid-ask spread and the rate of order cancellations and revisions, which is highlighted in Eq. (2). If the bid-ask spread is wide, the expected cost of being picked off and the expected cost of non-execution are low, and optimal $\lambda_{s}$ and $\lambda_{b}$ are small. Notice that this hypothesis highlights a relation different from the empirical results of Coppejans and Domowitz (2002) and Ellul, Holden, Jain, and Jennings (2007), who find a positive and dynamic relation between spread and limit order cancellation rates. When the spread is wide, the number of cancellations increases because traders will try to reposition their orders inside the spread to increase execution probability. In contrast to their arguments, which ignore FTO risk, I emphasize the ability of traders to compare two different ways of mitigating FTO cost and nonexecution cost: either widen the spread, lowering the marginal benefits of monitoring, or narrow the spread, increasing the marginal benefits of monitoring. If the latter strategy is employed, $\lambda_{s}$ and $\lambda_{b}$ will increase.

Hypothesis 2. On average, wide-spread stocks are associated with less order cancellation and revision activities.

Differentiating $\lambda_{s}$ and $\lambda_{b}$ with respect to $c$ yields

$$
\frac{\partial \lambda_{s}}{\partial c}=\frac{\partial \lambda_{b}}{\partial c}=-\left[\left[\frac{(1-\alpha) \beta}{2 \alpha}+1\right]^{2}-\frac{(1-\alpha) \beta \sigma}{c}\right]^{-\frac{1}{2}} \frac{(1-\alpha) \beta \sigma}{c^{2}}<0
$$

\footnotetext{
${ }^{10}$ Brockman and Chung (2000) use the trading model developed in Easley, Kiefer, O'Hara, and Paperman (1996) to examine the trading behaviors of privately informed and uninformed (liquidity) traders on the Stock Exchange of Hong Kong. They find that the arrival rate of uninformed trading is higher for large and actively traded stocks.
} 
The negative relation between $c$ and $\lambda_{s}$ or $\lambda_{b}$ suggests that stocks with a high cost of monitoring for public information releases will have a lower cancellation/revision rate. Large stocks have more intense order cancellation and revision activities than small stocks, because the cost of extracting information is lower for large stocks (Bhushan, 1989; Freeman, 1987). Also, large firms are likely to release more public information and have more financial press coverage than small firms (Gadarowski, 2002). ${ }^{11}$ It is expected that large firms receive more extensive analyst coverage through higher demand for analyst service from institutional investors. More significant information flows imply greater cancellation and revision activities, which yields:

Hypothesis 3. On average, large stocks are associated with more intense order cancellation and revision activities.

\section{Empirical tests}

The hypotheses developed in the previous section predict relations between proxies for limit order submission risks and cancellation/revision activities (measured by the number of limit order cancellations and revisions). Because the dependent variable of interest is the number of times an event occurs in a given time interval, count regression models are used to test the hypotheses. Unlike the dependent variable in the classical regression model, the dependent variable in this study consists only of non-negative integers. The benchmark model for the count regression models is the Poisson count regression model. This model is used extensively in biostatistics, labor economics, demographic economics, political science, sociology and finance. ${ }^{12}$ However, the assumption of equidispersion of the Poisson model is often too restrictive. So, to alleviate the problem of overdispersion in the data, I use the negative binomial (NB) model, which is a generalization of the Poisson model.

\subsection{Negative binomial count regression model}

Suppose, the number of event counts $y_{i t}$ follows a Poisson distribution with parameter $\theta_{i t}$. Given a vector of covariates $(N \times 1) \mathbf{x}_{i t}$ and $(M \times 1) \mathbf{z}_{i}, \theta_{i t}$ is given by

$$
\theta_{i t}=\exp \left(\boldsymbol{\beta}^{\prime} \mathbf{x}_{i t}+\gamma^{\prime} \mathbf{z}_{i}+\varepsilon_{i t}\right)=\mu_{i t} v_{i t}
$$

where $v_{i t}=\exp \left(\varepsilon_{i t}\right)$ and $\mu_{i t}=\exp \left(\boldsymbol{\beta}^{\prime} \mathbf{x}_{i t}+\boldsymbol{\gamma}^{\prime} \mathbf{z}_{i}\right)$. The parameter $\boldsymbol{\beta}_{i}^{\prime}$ is a $1 \times N$ vector. The covariate $\mathbf{z}_{i}$ captures the time invariant firm-specific attribute. The inclusion of $\mathbf{z}_{i}$ has the advantage of taking account of inter-firm variations, which enables the testing of Hypotheses 2 and 3. The procedure is similar to the maximum likelihood estimation of the fixed effects count model of panel data. To avoid confusion, I call this the individual effects

\footnotetext{
${ }^{11}$ The relation between firm size and the level of analyst coverage is supported by the empirical findings of Bhushan (1989), Hong, Lim, and Stein (2000) and Rock, Sedo, and Willenborg (2001). In particular, Hong, Lim, and Stein (2000) examine nine models of the cross-sectional determinants of analyst coverage, and report that firm size alone yields an $R^{2}$ of 0.61 , while other variables such as the book-to-market ratio, stock price, industry dummies, stock option dummies, trading turnover and lagged stock returns produce only a marginal increase in $R^{2}$.

${ }^{12}$ Cameron and Trivedi (1998) and Winkelmann (1997) provide an excellent survey of the literature on the count regression model. Recent applications of the model in the field of finance are discussed in Cameron and Trivedi (1996). Application of these models in the area of market microstructure is limited.
} 
model. ${ }^{13}$ Unlike the standard Poisson model, $\theta_{i t}$ is not a constant because it has a random term $\varepsilon_{t}$. To obtain an explicit density function, $v_{i t}$ is assumed to follow a two-parameters gamma distribution $\left(\alpha^{-1}, \alpha^{-1}\right)$ so that $E\left[v_{i t}\right]=1$ and $\operatorname{var}\left[v_{i t}\right]=\alpha$. The marginal distribution of event counts $y_{i t}$ is obtained by integrating out $v_{i t}$. After considerable algebra (see Cameron and Trivedi, 1998), the probability function is given by

$$
f\left(y_{i t} \mid \mathbf{x}_{i t}, \mathbf{z}_{i}, \alpha\right)=\frac{\Gamma\left(y_{i t}+\alpha^{-1}\right)}{\Gamma\left(y_{i t}+1\right) \Gamma\left(\alpha^{-1}\right)}\left(\frac{\alpha^{-1}}{\lambda_{i t}+\alpha^{-1}}\right)^{\alpha^{-1}}\left(\frac{\lambda_{i t}}{\lambda_{i t}+\alpha^{-1}}\right)^{y_{i t}}
$$

for $\alpha>0$. This Poisson-gamma mixture is known as the negative binomial distribution (Greenwood and Yule, 1920). The conditional expected value of $y_{i t}$ is $E\left[y_{i t} \mid \mathbf{x}_{i t}, z_{i}, \alpha\right]=\mu_{i t}$ and the conditional variance is $\operatorname{var}\left[y_{i t} \mid \mathbf{x}_{i t}, z_{i}, \alpha\right]=\mu_{i t}\left(1+\alpha \mu_{i t}\right)$. Note that the additional parameter $\alpha$ yields the dispersion factor $1+\alpha \mu_{i t}$, which captures the overdispersion in the data. ${ }^{14}$ This model should fit the data reasonably well when there is a large proportion of zeros, which in this application can be caused by the infrequent arrival of information and the lower public interest in smaller stocks. This model can be regarded as a generalization of the Poisson model since it can be shown that the geometric and the Poisson distributions are special cases of the negative binomial distribution.

The log-likelihood function is expressed as

$$
\begin{aligned}
\ln \mathscr{L}= & \sum_{i=1}^{M} \sum_{t=1}^{T}\left(\left(\sum_{j=0}^{y_{i t}-1} \ln \left(j+\alpha^{-1}\right)\right)-\ln y_{i t} !\right. \\
& \left.-\left(\alpha^{-1}+y_{i t}\right) \ln \left(\alpha \mathrm{e}^{\boldsymbol{\beta}^{\prime} \mathbf{x}_{i t}+\gamma^{\prime} \mathbf{z}_{i}}+1\right)+y_{i t} \ln \alpha+y_{i t}\left(\boldsymbol{\beta}^{\prime} \mathbf{x}_{i t}+\gamma^{\prime} \mathbf{z}_{i}\right)\right) .
\end{aligned}
$$

The first order conditions of the log-likelihood function yield the maximum likelihood estimators $\hat{\boldsymbol{\beta}}, \hat{\boldsymbol{\gamma}}$ and $\hat{\alpha}$. If the density is correctly specified, $\hat{\boldsymbol{\beta}}, \hat{\boldsymbol{\gamma}}$ and $\hat{\alpha}$ are consistent for $\boldsymbol{\beta}, \boldsymbol{\gamma}$ and $\alpha$ under usual regularity conditions. The asymptotic variance-covariance matrix of the estimators is derived in a similar way. When we estimate the model using panel data, our dependent variables are clustered into groups of firms and it is likely that $y_{i t}$ invalidates the independent distributed assumption. As a result, the estimates of $\boldsymbol{\beta}$ and $\boldsymbol{\gamma}$ need not be consistent. To account for this potential problem, robust asymptotic covariance matrix estimators (or the robust sandwich estimators) that consider group effects are obtained. ${ }^{15}$

\footnotetext{
${ }^{13}$ In some respects, this approach is similar to the standard maximum likelihood estimation of the fixed effects model, where a dummy variable is given for every firm. In my case, I use firm size and average bid-ask spread in lieu of dummy variables to capture inter-firm variations. I do not consider the fixed effects model because of the strict multicollinearity between the dummy variables, and time invariant firm variables and their effects cannot be disentangled.

${ }^{14}$ This standard negative binomial model is also known as NB2 in Cameron and Trivedi (1986, 1998).

${ }^{15}$ The inclusion of time-invariant variables in the negative binomial model achieves results that are qualitatively similar to a negative binomial model with fixed effects. We also consider the negative binomial model with random effects when the uncaptured firm attribute is treated as a random variable. However, the Hausman test rejected the model, as the orthogonality condition on the random effects component with the regressors is not satisfied. Results are not reported.
} 


\section{Dataset}

I use the order flow data from 23 actively traded stocks on the Australian Stock Exchange (ASX). The dataset is unique because it distinguishes order cancellations from order revisions. ${ }^{16}$ In addition, the dataset divides order revisions into three broad types: order quantity revisions; limit price revisions; and conversions from a limit order to a market order. Strictly speaking, the last type is a special case of the second type, where the limit price is amended to match the market price. During 1999, a total of 2.98 million orders were recorded for the 23 stocks. This total comprises 1.09 million limit order submissions, 1.13 million market order submissions, 0.39 million limit order revisions based on prices (which includes conversion to market orders), 0.10 million limit order revisions based on order size, and 0.27 million limit order cancellations. The total of limit order cancellations includes both automatic cancellations due to expiration and deliberate cancellations. Analysis of revisions to order quantity is left for future research. ${ }^{17}$

On the ASX, orders may be entered, revised or withdrawn at any time between 7:00 and 17:00 by brokers, or by clients who use 'straight-through' order entry software provided by a broker (known as an 'online broker'). In the latter case, investors can submit, revise and cancel orders almost instantaneously, subject to the reliability of their broker's order entry software, their internet connection and the volume of internet traffic. All price revisions receive the lowest time priority at the revised price, following the price-time priority rules of the exchange. If a trader increases the volume of the entered order at the same price, the trading system automatically creates a new order which receives the lowest time priority at that price. However, if the volume is decreased, the order retains its time priority. A market order cannot be canceled or revised upon submission since it receives immediate execution.

All entered limit orders have 'expiry dates'. A 'day-only' limit order is canceled automatically at the end of the trading day, while a 'fill-or-kill' limit order is canceled automatically after about nine weeks. In addition, at 19:00, any order with a limit price that is too far from the market price is canceled automatically by the system, unless it is the only order left in the queue for that stock. All entered orders are charged at $\$ 0.22$ per order by the ASX to the broker but any subsequent price or volume revision or cancellation is free of charge. Typically, brokerage fees are incurred only when a trade is completed.

The order flow dataset is provided by the Securities Industry Research Centre of AsiaPacific (SIRCA). It contains a complete record of the order flow for 23 companies, traded on the ASX, from 4 January 1999 to 31 December 1999. The stocks are randomly selected from the top 50 ASX-listed stocks in terms of market capitalization. They belong to a range of industries. Table 1 provides a list of the sample stocks, together with their industry classification. These stocks are actively traded in the market and are closely followed by brokers, financial analysts and fund managers.

The original SIRCA dataset records each order and trade including the date, time to the nearest hundredth of second, stock code, price, transacted volume and order type. Orders

\footnotetext{
${ }^{16}$ Unfortunately I am unable to identify orders that are canceled and resubmitted because resubmitted orders receive a different cross-reference number.

${ }^{17}$ One possible explanation for order quantity revision is that large traders attempt to minimize the price impact of their orders by first placing a small order and then sequentially " refilling" the order quantity when the small order is partially executed.
} 
Table 1

Sample stocks

\begin{tabular}{|c|c|c|c|}
\hline Company & Industry & Ave. market cap. $\$ M$ & $\begin{array}{l}\text { Total no. of sample } \\
\text { intervals after deleting } \\
\text { days with trading halts }\end{array}$ \\
\hline NAB & Banking & $37,116.81$ & 1410 \\
\hline NCP & Media & $25,076.56$ & 1446 \\
\hline WBC & Banking & $19,534.39$ & 1434 \\
\hline RIO & Materials & $15,003.52$ & 1386 \\
\hline CML & Retailing & 9721.45 & 1470 \\
\hline FBG & Food, Beverage \& Tobacco & 7696.11 & 1422 \\
\hline WMC & Materials & 7393.32 & 1422 \\
\hline SGB & Banking & 4813.45 & 1422 \\
\hline WFT & Real Estate & 4762.04 & 1488 \\
\hline $\mathrm{NMH}$ & Insurance & 4432.01 & 1464 \\
\hline $\mathrm{CMC}$ & Materials & 4017.87 & 1488 \\
\hline GPT & Real Estate & 3763.74 & 1440 \\
\hline SRP & Food, Beverage \& Tobacco & 3643.23 & 1458 \\
\hline WES & Capital Goods & 3619.95 & 1470 \\
\hline TAH & Hotel, Restaurant \& Leisure & 3444.19 & 1458 \\
\hline MBL & Banking & 3288.27 & 1470 \\
\hline AGL & Utilities & 3285.51 & 1380 \\
\hline HVN & Retailing & 3019.38 & 1476 \\
\hline PDP & Health Care Equipment \& Service & 2532.48 & 1452 \\
\hline AFI & Diversified Financial & 1935.38 & 1500 \\
\hline SME & Diversified Financial & 1913.79 & 1470 \\
\hline GMF & Food, Beverage \& Tobacco & 1879.26 & 1464 \\
\hline MAY & Health Care Equipment \& Service & 1752.38 & 1476 \\
\hline All stocks & & & 33,366 \\
\hline
\end{tabular}

This table provides a summary of the sample stocks. The industry classification is based on Global Industry Classification Standard (GICS). The average market capitalization is based on the daily average of the number of shares outstanding multiplied by the daily closing stock price. We define an interval with a trading halt during the normal trading hours if negative bid-ask spreads are found within that interval.

that are amended (either order price or order volume or both) after the original submission are recorded.

To extract data in a format that is suitable for empirical investigation, I use a program to reconstruct the limit order book from the original order flow data. The program mimics the order matching algorithm operated by SEATS, and generates a snapshot of the limit order book at any given point in time. To achieve the highest level of precision, the bid-ask spread of the regenerated limit order book is checked to ensure that it matches the bid-ask spread reported in the SIRCA order flow data. Once the limit order book construction is verified, the program then computes and extracts relevant data, including the number of limit order cancellations and limit price revisions in each one-hour interval during normal trading hours and during the pre-opening phase.

I divide each trading day into seven intervals. The first interval is the pre-opening interval from 7:00 to 10:00, when order submissions, revisions and cancellations are allowed. The first interval also records limit orders that are deleted automatically from the trading system because their limit prices are too far from market prices, and all automatic 
cancellations that occur at 19:00 on the previous day. The remaining six intervals are onehour intervals during the normal trading mode, starting at 10:00 and ending at 16:00. Because no orders are executed during the pre-opening interval, the inclusion of cancellations and revisions that occur in this period would bias our results. In total, the sample contains 252 trading days for 23 companies, giving 5796 company/day pairs. Due to faulty data, two of these pairs are discarded: they are 26 April 1999 for FBG and 1 April 1999 for SGB. This leaves a total of 34,764 hourly intervals (5794 pairs $\times 6$ intervals). In addition, for all first intervals of the day, I consider only cancellations and revisions after the opening procedure is complete, at around 10:09am. ${ }^{18}$ Therefore, I discard all automatic cancellations that occurred after hours or before the market opened. I do not consider institutional trades conducted off the market because the terms of these trades are negotiated privately and the resulting prices are often priced away from the market.

Variations in tick sizes might present a problem because tick size is negatively related to the equilibrium number of order revisions. Cordella and Foucault (1999) develop a model of competitive bidding between two dealers. They show that in the absence of information arrival, the speed of convergence of a dealer's quotes to the competitive bid and ask prices increases with tick size. When the tick size is small, the dealer may find it profitable to undercut by one tick rather than to post the competitive price, thus increasing the frequency of quote revisions. To avoid the potential impact of different tick sizes on the number of cancellations and revisions, all stocks in the sample have a common tick size of one cent, since all of their order prices exceed $\$ 0.50 .{ }^{19}$

In the ASX, a crossing occurs when a broker has a matching buy and a matching sell order in his book. The presence of "crossing" trades in the ASX may inflate the number of order cancellations, because for each crossing trade brokers are required by the ASX to place an artificial limit order to create a crossing market, which is generally followed by an immediate cancellation of that order. The inclusion of these artificial cancellations may bias the results. To mitigate this potential problem, we remove all single share order submissions and cancellations from our dataset.

The presence of trading halts may also create biases as they could potentially confound the relation between order cancellations/revisions and option values. A trading halt is a temporary break in the trading of a company's securities. The length of a trading halt is usually ten minutes, but varies depending on the nature of the halt. When a trading halt is imposed, the stock exchange will place the trading of the securities into the pre-opening phase; that is, no trading is allowed but orders can be entered, cancelled and revised. Because of the increase in the number of cancellations/revisions associated with a halt (during and after the halt), the entire trading day is eliminated from the sample if a trading

\footnotetext{
${ }^{18}$ In the ASX, the market opens at 10:00 with a call auction to clear all limit orders with overlapping prices. These overlapping orders are filled at their volume-weighted average price. The opening price determined by this algorithm is the volume-weighted average of the last pair of matched overlapping limit orders. This last pair is the pair of overlapping orders just before the priority buy price is less than the priority sell price. For each stock, the opening algorithm ends when all overlapping orders are filled, which occurs at around 10:09. The unfilled limit orders are left in the limit order book.

${ }^{19}$ In the ASX, the minimum price increment (tick size) differs depending on the order prices. For order prices that are less than $\$ 0.10$, the tick size is $\$ 0.001$. For order prices ranging from $\$ 0.10$ to $\$ 0.50$, the tick size is $\$ 0.005$. For order prices exceeding $\$ 0.50$, the tick size is $\$ 0.01$.
} 
halt is recorded during that day. ${ }^{20}$ This has resulted in the removal of 233 trading days on which trading was halted, reducing the number of sample intervals from 34,764 to 33,366.

\subsection{Dependent variables}

The dependent variables under investigation are the total number of (i) limit buy order cancellations, (ii) limit sell order cancellations, (iii) limit buy order revisions, and (iv) limit sell order revisions, that arrived in every one-hour interval. Only revisions of the limit price, which includes all conversions from a limit order to a market order (which is commonly known as a marketable limit order), are included. Revisions of order quantity are not considered.

\subsection{Independent variables}

The following covariates are used to test Hypotheses 1-3.

FTO risk for limit sell orders: The intrinsic value of the option based on the change of the mid-quote prices is used to examine the relation between free option risk and the number of order cancellations/revisions (Hypothesis 1a). As discussed earlier, a limit sell order is analogous to writing a free call option. Therefore, the intrinsic value of this call option for stock $i$ at time $t$ is given by

$$
C A L L_{i, t}=\max \left[P_{i, t+1}-A_{i, t}, 0\right],
$$

where $P_{i, t+1}$ is the average mid-quote price in the one-hour interval $t+1$. Let $A_{i, t, \tau}$ and $B_{i, t, \tau}$ be the best ask and best bid prices respectively, at the end of subinterval $\tau$ in the one-hour interval $t$,

$$
P_{i, t}=\frac{1}{12} \sum_{\tau=1}^{12} \frac{\left(A_{i, t, \tau}+B_{i, t, \tau}\right)}{2} .
$$

Each subinterval $\tau$ is five minutes in length. $A_{i, t}$ is the average of the 12 five-minute snapshots of the best ask price of stock $i$ in the interval $t$. Limit sell orders are susceptible to being picked off only if the mid-quote increases by more than half of the spread. The use of average five-minutes mid-quote price and spread minimizes the possibility that the option value is artificially affected by the cancellation at the best quote.

FTO risk for limit buy orders: The intrinsic value of the put option (for limit buy orders) is computed in a similar fashion;

$$
P U T_{i, t}=\max \left[B_{i, t}-P_{i, t+1}, 0\right],
$$

where $B_{i, t}$ is the average of the 12 five-minute snapshots of the best bid price of stock $i$ in the interval $t$.

Non-execution risk for limit sell orders: The relation between the non-execution risk and the number of order cancellations/revisions (Hypothesis $1 \mathrm{~b}$ ) is calculated by computing the

\footnotetext{
${ }^{20}$ To check if the number of orders cancelled and revised surrounding the trading halt is significantly different from the matched sample, I follow Corin and Lipson's (2000) approach to compute the abnormal statistics of limit order cancellations and revisions two hours before, during, and two hours after the interval that consist of a trading halt (results not reported). I find a noticeable increase in order cancellations and revisions surrounding the halt.
} 
non-execution cost due to price changes. Because of the symmetry between FTO risk and non-execution risk, the non-execution risk for a limit sell order is increasing in the intrinsic value of the free put option, which is proxied by

$$
P U T_{i, t}=\max \left[B_{i, t}-P_{i, t+1}, 0\right] \text {. }
$$

Non-execution risk for limit buy orders: The non-execution risk for a limit buy order is increasing in the intrinsic value of the free call option, which is proxied by

$$
C A L L_{i, t}=\max \left[P_{i, t+1}-A_{i, t}, 0\right] \text {. }
$$

Quoted spread: To test Hypothesis 2, I derive the quoted bid-ask spread for each interval by averaging 12 five-minute quoted spreads within that interval. This variable $\left(Q S_{i}\right)$ is given by

$$
Q S_{i}=\frac{1}{T} \frac{1}{12} \sum_{t=1}^{T} \sum_{\tau=1}^{12} A_{i, t, \tau}-B_{i, t, \tau} .
$$

Again, each subinterval $\tau$ is five minutes in length and we have 12 subintervals for each one-hour interval $t$. One disadvantage of this quoted spread measure is that it does not explicitly incorporate market depth. If the volume of the best bid or best ask price is small, there may be no significant liquidity available, hence the quoted spread can systematically under-estimate the "true" spread. In reality, a sufficiently large market order can lead to an execution at an inferior term because the marginal price can be higher (lower) than the best ask (best bid). Therefore, a better measure is the effective spread.

Effective spread: The effective spread measures the difference between the most recent trade price and the midquote price:

$$
E S_{i}=\frac{1}{T} \frac{1}{12} \sum_{t=1}^{T} \sum_{\tau=1}^{12} P_{i, t, \tau}-P_{i, t, \tau}^{\text {trade }} .
$$

$P_{i, t, \tau}$ is the midquote price at the end of subinterval $\tau$ in the one-hour interval $t$, i.e., $P_{i, t, \tau}=A_{i, t, \tau}-B_{i, t, \tau} . P_{i, t, \tau}^{\text {trade }}$ is the most recent trade price in the subinterval $\tau$ in the one-hour interval $t$.

Firm size: For each stock, the logarithm of average market capitalizations (based on daily share prices and the number of shares outstanding) in the year 1999 is used as a proxy for firm size $\left(S I Z E_{i}\right)$.

Time-of-the-day dummies: I control for the unexplained U-shaped time-of-the-day pattern of order cancellations and revisions by imposing dummy variables $D(1)_{i, t}, D(2)_{i, t}$, $D(4)_{i, t}, D(5)_{i, t}$ and $D(6)_{i, t}$, if, respectively, cancellations and revisions occur from 10:09 to 11:00 am, from 11:00 to 12:00 noon, from 1:00 to 2:00 pm, from 2:00 to 3:00 pm and from 3:00 to $4: 00 \mathrm{pm}$. The use of time-of-the-day dummy variables also has the advantage of mitigating the potential problem of spurious regression arising from independent variables.

Quote depth: As reported in numerous empirical studies, book depth affects the rate of order submission and cancellation (see Biais, Hillion, and Spatt, 1995; Coppejans and Domowitz, 2002; Ranaldo, 2004). Traders cancel and resubmit their orders at favorable prices when the limit order book exhibit temporary "holes" . Buy (sell) order cancellations increase when the bid (ask) depth is deep and when the ask (bid) depth is small. To derive a measure of quote depth, I compute the average total number of limit orders outstanding in the limit order book based on a five-minute snap shot of the limit order book. For each 


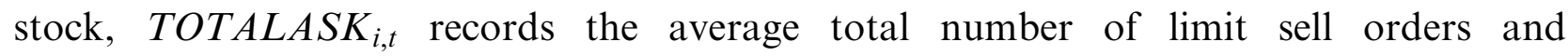
TOTALBID ${ }_{i, t}$ records the average total number of limit buy orders in the book in the interval $t$.

\subsection{Summary statistics}

After excluding orders on days with trading halts and in all pre-opening intervals, 2.52 million order entries are recorded for the 23 sample stocks. Of these, $8.54 \%$ are canceled orders, while $7.51 \%$ are revised orders based on price revision. There are slightly more buy cancellations and revisions than their sell counterparts: $51.78 \%$ of all cancellations are buy cancellations, while $50.68 \%$ of all order price revisions are buy revisions.

Summary statistics for all variables are provided in Table 2. The use of the count regression model in estimating the number of order cancellations and revisions is supported by the excessive kurtosis (leptokurtic) and positively skewness found in the dependent variable. The table also contains the average intraday value of each variable.

It can be seen that the average counts of all four order events ( $L B C, L S C, L B R$ and $L S R$ ) exhibit a U-shaped pattern. The number of cancellations and revisions is substantially lower during lunch hours than other hours. Such a pattern may be attributed to the closure of the Exchange Traded Option market between 12:30 and 14:00. While most stocks in the sample tend to have a liquid options market, which may be an important source of information for price discovery, the absence of the derivative market during the lunch hour could reduce the possibility of acquiring important information. Thus, there may be fewer order cancellations and revisions during these intervals.

A possible explanation for increasing cancellation and revision activities toward the last hours of the trading horizon is that traders who have a deadline to complete the trade

Table 2

Summary statistics of dependent and independent variables

\begin{tabular}{|c|c|c|c|c|c|c|c|c|c|c|c|}
\hline Interval & $L B C$ & $L S C$ & $L B R$ & $L S R$ & $C A L L$ & PUT & $Q S$ & $R S$ & SIZE & TOTAL BID & TOTAL $A S K$ \\
\hline 1 & 4.37 & 4.06 & 8.71 & 8.41 & 0.0111 & 0.0121 & - & - & - & 115.21 & 87.57 \\
\hline 2 & 3.58 & 3.31 & 5.37 & 5.10 & 0.0087 & 0.0087 & - & - & - & 116.19 & 88.87 \\
\hline 3 & 1.96 & 1.79 & 3.02 & 2.70 & 0.0035 & 0.0028 & - & - & - & 117.13 & 89.88 \\
\hline 4 & 0.92 & 0.72 & 1.57 & 1.34 & 0.0050 & 0.0067 & - & - & - & 118.49 & 90.75 \\
\hline 5 & 3.89 & 3.70 & 5.29 & 5.39 & 0.0084 & 0.0098 & - & - & - & 118.24 & 91.11 \\
\hline 6 & 5.30 & 5.08 & 8.59 & 7.96 & 0.0373 & 0.0304 & - & - & - & 117.20 & 90.65 \\
\hline Mean & 3.34 & 3.11 & 5.50 & 5.23 & 0.0122 & 0.0116 & 0.0264 & 0.0296 & 22.31 & 116.45 & 89.46 \\
\hline S.D. & 4.56 & 4.26 & 7.64 & 6.85 & 0.0505 & 0.0809 & 0.0191 & 0.0375 & 0.83 & 132.60 & 71.46 \\
\hline Skewness & 2.80 & 2.55 & 23.40 & 16.17 & 19.55 & 127.32 & 1.2827 & 2.4349 & 0.94 & 2.64 & 1.13 \\
\hline Kurtosis & 15.54 & 12.51 & 3.54 & 3.11 & 874.83 & 20381.87 & 3.1953 & 8.8037 & 3.00 & 12.00 & 4.23 \\
\hline
\end{tabular}

This table presents the average intraday values for each variable (six one-hour intervals between 10:00 and 16:00) and their respective summary statistics. $L B C, L S C, L B R$ and $L S R$ are the number of limit buy order cancellations, limit sell order cancellations, limit buy order revisions and limit sell order revisions, respectively, for each one-hour interval; CALL and PUT are the respective free call option and free put option values, given by Eqs. (5) and (6); $Q S$ and $E S$ are the average quoted spread and the average effective spread; $S I Z E$ is the logarithm of the market capitalization for the year 1999. TOTALBID and TOTALASK are the verage no. of "live" limit buy and limit sell orders outstanding in the interval. PRICE is the average level of stock price. 
Table 3

Results of the negative binomial count regression of the number of limit buy order cancellations (LBC)

\begin{tabular}{|c|c|c|c|c|c|c|c|c|c|c|c|c|c|c|}
\hline & $N A B$ & $N C P$ & $W B C$ & $R I O$ & $C M L$ & $F B G$ & $W M C$ & $S G B$ & $W F T$ & $N M H$ & $C M C$ & $G P T$ & $S R P$ & WES \\
\hline$D(1)$ & $\begin{array}{l}0.8025 \\
(13.25)\end{array}$ & $\begin{array}{l}0.9237 \\
(14.58)\end{array}$ & $\begin{array}{l}0.8764 \\
(16.31)\end{array}$ & $\begin{array}{l}0.9730 \\
(12.97)\end{array}$ & $\begin{array}{l}0.7391 \\
(12.10)\end{array}$ & $\begin{array}{l}0.8153 \\
(11.03)\end{array}$ & & & & $\begin{array}{c}0.5032 \\
(4.91)\end{array}$ & & & & $\begin{array}{l}0.3957 \\
(3.37)\end{array}$ \\
\hline$D(2)$ & $\begin{array}{c}0.5548 \\
(9.32)\end{array}$ & $\begin{array}{l}0.6959 \\
(10.77)\end{array}$ & $\begin{array}{l}0.6774 \\
(12.12)\end{array}$ & $\begin{array}{c}0.6679 \\
(9.37)\end{array}$ & $\begin{array}{c}0.5299 \\
(8.16)\end{array}$ & $\begin{array}{l}0.4717 \\
(6.60)\end{array}$ & $\begin{array}{l}0.7246 \\
(10.36)\end{array}$ & $\begin{array}{l}0.6112 \\
(6.89)\end{array}$ & $\begin{array}{l}0.6865 \\
(6.50)\end{array}$ & $\begin{array}{l}0.5157 \\
(4.95)\end{array}$ & $\begin{array}{l}0.6565 \\
(5.47)\end{array}$ & $\begin{array}{c}0.6293 \\
(5.27)\end{array}$ & $\begin{array}{l}0.4698 \\
(4.66)\end{array}$ & $\begin{array}{l}0.4352 \\
(3.81)\end{array}$ \\
\hline$D(4)$ & $\begin{array}{l}-0.8510 \\
(-11.82)\end{array}$ & $\begin{array}{l}-0.9932 \\
(-10.15)\end{array}$ & $\begin{array}{l}-0.8193 \\
(-11.35)\end{array}$ & $\begin{array}{l}-1.0390 \\
(-9.83)\end{array}$ & $\begin{array}{c}-0.4283 \\
(-5.43)\end{array}$ & $\begin{array}{l}-0.5840 \\
(-6.66)\end{array}$ & $\begin{array}{c}-0.8372 \\
(-9.12)\end{array}$ & $\begin{array}{l}-0.8181 \\
(-7.04)\end{array}$ & $\begin{array}{c}-0.9843 \\
(-5.88)\end{array}$ & $\begin{array}{l}-0.6228 \\
(-4.79)\end{array}$ & $\begin{array}{c}-1.4666 \\
(-7.08)\end{array}$ & $\begin{array}{l}-0.7453 \\
(-4.97)\end{array}$ & $\begin{array}{c}-0.8246 \\
(-6.71)\end{array}$ & $\begin{array}{l}-0.6899 \\
(-4.73)\end{array}$ \\
\hline$D(5)$ & & & & & & & & & & & & & & \\
\hline$D(6)$ & & $\begin{array}{l}0.9721 \\
(11.16)\end{array}$ & & & & & & & & & & & & \\
\hline TOTALBID & $\begin{array}{c}0.0007 \\
(5.81)\end{array}$ & $\begin{array}{c}0.0029 \\
(5.59)\end{array}$ & $\begin{array}{c}0.0006 \\
(4.62)\end{array}$ & $\begin{array}{c}0.0036 \\
(1.69)\end{array}$ & $\begin{array}{c}0.0002 \\
(2.31)\end{array}$ & $\begin{array}{c}0.0003 \\
(1.91)\end{array}$ & $\begin{array}{c}-0.0003 \\
(0.84)\end{array}$ & & $\begin{array}{l}-0.0025 \\
(-0.64)\end{array}$ & $\begin{array}{c}0.0035 \\
(3.69)\end{array}$ & $\begin{array}{c}0.0143 \\
(3.55)\end{array}$ & $\begin{array}{l}0.0025 \\
(1.00)\end{array}$ & $\begin{array}{c}-0.0008 \\
(-0.82)\end{array}$ & $\begin{array}{l}-0.0002 \\
(-0.10)\end{array}$ \\
\hline TOTALASK & $\begin{array}{l}-0.0015 \\
(-4.18)\end{array}$ & $\begin{array}{l}-0.0033 \\
(-4.02)\end{array}$ & $\begin{array}{l}-0.0010 \\
(-6.49)\end{array}$ & $\begin{array}{l}-0.0046 \\
(-2.91)\end{array}$ & $\begin{array}{c}0.0002 \\
(0.59)\end{array}$ & $\begin{array}{l}-0.0002 \\
(-0.30)\end{array}$ & $\begin{array}{l}-0.0012 \\
(-2.86)\end{array}$ & $\begin{array}{l}-0.0060 \\
(-5.14)\end{array}$ & $\begin{array}{l}-0.0067 \\
(-1.22)\end{array}$ & $\begin{array}{l}-0.0007 \\
(-0.73)\end{array}$ & $\begin{array}{l}-0.0444 \\
(-7.00)\end{array}$ & $\begin{array}{l}0.0047 \\
(1.69)\end{array}$ & $\begin{array}{l}-0.0023 \\
(-1.96)\end{array}$ & $\begin{array}{l}-0.0122 \\
(-2.95)\end{array}$ \\
\hline$C A L L$ & & & & & & & & & & & & $\begin{array}{c}6.9208 \\
(1.38)\end{array}$ & $\begin{array}{c}4.7245 \\
(2.88)\end{array}$ & $\begin{array}{l}1.8361 \\
(4.12)\end{array}$ \\
\hline PUT & $\begin{array}{c}0.4826 \\
(1.52)\end{array}$ & $\begin{array}{l}0.5496 \\
(0.99)\end{array}$ & $\begin{array}{l}0.5052 \\
(0.90)\end{array}$ & $\begin{array}{c}0.7068 \\
(3.64)\end{array}$ & $\begin{array}{c}-0.8608 \\
(-1.29)\end{array}$ & $\begin{array}{c}0.7490 \\
(0.60)\end{array}$ & $\begin{array}{l}2.8213 \\
(4.24)\end{array}$ & $\begin{array}{l}1.6170 \\
(2.44)\end{array}$ & $\begin{array}{l}1.7919 \\
(0.56)\end{array}$ & $\begin{array}{c}6.3059 \\
(1.66)\end{array}$ & $\begin{array}{l}1.0102 \\
(0.97)\end{array}$ & $\begin{array}{l}8.8398 \\
(2.10)\end{array}$ & $\begin{array}{l}1.6991 \\
(1.15)\end{array}$ & $\begin{array}{l}0.8968 \\
(2.01)\end{array}$ \\
\hline Constant & $\begin{array}{l}1.8426 \\
(33.08)\end{array}$ & $\begin{array}{l}1.4806 \\
(20.13)\end{array}$ & $\begin{array}{l}1.4774 \\
(23.69)\end{array}$ & $\begin{array}{l}1.1486 \\
(10.90)\end{array}$ & $\begin{array}{l}0.9120 \\
(10.24)\end{array}$ & $\begin{array}{l}0.9661 \\
(12.10)\end{array}$ & $\begin{array}{l}1.5255 \\
(13.83)\end{array}$ & $\begin{array}{l}0.6783 \\
(4.44)\end{array}$ & $\begin{array}{l}0.0324 \\
(0.18)\end{array}$ & $\begin{array}{l}-0.0929 \\
(-0.50)\end{array}$ & $\begin{array}{l}-0.0508 \\
(-0.35)\end{array}$ & $\begin{array}{l}-0.5724 \\
(-3.38)\end{array}$ & $\begin{array}{c}0.4493 \\
(3.25)\end{array}$ & $\begin{array}{l}0.1844 \\
(1.32)\end{array}$ \\
\hline Log likelihood & -4180 & -4000 & -3791 & -3536 & -3476 & -3429 & -3883 & -2644 & -2388 & -2450 & -1965 & -2203 & -2576 & -2205 \\
\hline Pearson $R^{2}$ & 0.80 & 0.79 & 0.75 & 0.77 & 0.64 & 0.70 & 0.83 & 0.60 & 0.53 & 0.53 & 0.57 & 0.52 & 0.58 & 0.56 \\
\hline alpha & 0.17 & 0.26 & & 0.28 & 0.24 & 0.3 & 0.35 & 0.33 & 0.41 & 0.44 & 0.63 & 0.43 & 0.44 & 0.76 \\
\hline 3rror & 0.01 & 0.02 & 0.01 & 0.02 & 0.02 & 0.02 & 0.02 & 0.03 & 0.04 & 0.05 & 0.07 & 0.05 & 0.04 & 0.07 \\
\hline$W A L D$ & 12.18 & 14.66 & 12.63 & 14.56 & 12.38 & 13.82 & 16.37 & 10.50 & 9.21 & 9.57 & 8.76 & 8.89 & 11.24 & 10.78 \\
\hline$L M$ & 38.68 & 43.00 & 22.48 & 33.27 & 22.27 & 27.60 & 50.86 & 15.24 & 15.34 & 16.04 & 14.15 & 13.32 & 17.20 & 20.79 \\
\hline$L R$ & 1150 & 1335 & 565 & 955 & 522 & 732 & 1808 & 295 & 248 & 278 & 248 & 209 & 350 & 395 \\
\hline
\end{tabular}




\begin{tabular}{|c|c|c|c|c|c|c|c|c|c|}
\hline & $T A H$ & $M B L$ & $A G L$ & $H V N$ & $P D P$ & $A F I$ & $S M E$ & $G M F$ & $M A Y$ \\
\hline \multirow[t]{2}{*}{$D(1)$} & 0.5362 & 0.3356 & 0.5637 & 0.4859 & 0.6749 & 0.7722 & 0.5353 & 0.8970 & 0.4464 \\
\hline & $(6.52)$ & $(3.31)$ & $(6.31)$ & $(3.95)$ & $(7.80)$ & $(4.63)$ & $(4.55)$ & $(10.45)$ & $(4.92)$ \\
\hline \multirow[t]{2}{*}{$D(2)$} & 0.4872 & 0.3726 & 0.4066 & 0.3393 & 0.5227 & 0.4585 & 0.4348 & 0.6530 & 0.5533 \\
\hline & $(5.79)$ & $(3.72)$ & $(4.50)$ & $(2.73)$ & $(5.72)$ & $(2.64)$ & $(4.00)$ & $(7.50)$ & $(6.00)$ \\
\hline \multirow[t]{2}{*}{$D(4)$} & -0.9056 & -0.9975 & -0.4311 & -0.6854 & -0.6398 & -0.4048 & -0.5288 & -0.4757 & -0.6211 \\
\hline & $(-8.33)$ & $(-7.49)$ & $(-4.31)$ & $(-4.44)$ & $(-5.77)$ & $(-1.94)$ & $(-3.68)$ & $(-4.45)$ & $(-5.37)$ \\
\hline \multirow[t]{2}{*}{$D(5)$} & 0.6226 & 0.5916 & 0.4088 & 0.4087 & 0.4479 & 0.6922 & 0.4005 & 0.5682 & 0.6223 \\
\hline & $(7.73)$ & (6.04) & $(4.48)$ & $(3.37)$ & $(5.14)$ & $(3.78)$ & $(3.57)$ & $(6.45)$ & $(6.43)$ \\
\hline \multirow[t]{2}{*}{$D(6)$} & 0.8676 & 0.8789 & 0.5817 & 0.8113 & 0.8685 & 1.0084 & 0.7152 & 0.8796 & 0.7877 \\
\hline & (10.67) & $(8.64)$ & $(5.99)$ & $(6.79)$ & $(9.56)$ & $(5.82)$ & $(6.02)$ & $(9.83)$ & $(8.02)$ \\
\hline \multirow[t]{2}{*}{ TOTALBID } & 0.0048 & 0.0108 & 0.0007 & 0.0029 & 0.0013 & 0.0037 & 0.0073 & 0.0015 & -0.0024 \\
\hline & $(5.27)$ & $(5.23)$ & $(3.36)$ & $(2.05)$ & $(4.88)$ & $(2.15)$ & $(2.90)$ & $(5.24)$ & $(-2.90)$ \\
\hline \multirow[t]{2}{*}{ TOTALASK } & -0.0011 & -0.0103 & -0.0027 & 0.0000 & -0.0018 & -0.0143 & -0.0052 & -0.0012 & -0.0024 \\
\hline & $(-1.22)$ & $(-3.03)$ & $(-3.77)$ & $(0.02)$ & $(-2.93)$ & $(-4.00)$ & $(-4.10)$ & $(-2.31)$ & $(-3.59)$ \\
\hline \multirow[t]{2}{*}{$C A L L$} & 2.9892 & 1.0387 & 2.8972 & 0.1724 & 13.7480 & 1.9857 & 3.9044 & 13.2218 & 8.6998 \\
\hline & $(6.49)$ & $(3.36)$ & $(3.71)$ & $(0.35)$ & $(4.25)$ & $(0.41)$ & $(2.96)$ & $(2.29)$ & $(4.82)$ \\
\hline \multirow[t]{2}{*}{$P U T$} & 0.2625 & 0.5157 & 0.7061 & 0.0486 & 3.3506 & 0.7178 & 1.6454 & 7.3670 & 2.2701 \\
\hline & $(0.41)$ & $(0.63)$ & $(0.92)$ & $(4.01)$ & $(1.11)$ & $(0.15)$ & $(0.85)$ & (1.94) & $(1.90)$ \\
\hline \multirow[t]{2}{*}{ Constant } & 0.4257 & 0.1058 & 0.6517 & -0.4397 & 0.4128 & -1.1069 & -0.2653 & 0.1706 & 0.8502 \\
\hline & $(5.17)$ & $(0.77)$ & (6.69) & $(-4.40)$ & (3.87) & $(-4.78)$ & $(-1.66)$ & $(1.49)$ & $(6.38)$ \\
\hline Log likelihood & -3116 & -2725 & -2722 & -2001 & -2696 & -1257 & -2082 & -2634 & -2833 \\
\hline Pearson $R^{2}$ & 0.68 & 0.56 & 0.65 & 0.50 & 0.59 & 0.40 & 0.55 & 0.53 & 0.66 \\
\hline$\alpha$ & 0.39 & 0.5 & 0.34 & 0.72 & 0.36 & 0.94 & 0.63 & 0.3 & 0.55 \\
\hline Std error $(\alpha)$ & 0.03 & 0.04 & 0.03 & 0.08 & 0.03 & 0.15 & 0.07 & 0.03 & 0.04 \\
\hline$W A L D$ & 13.01 & 12.37 & 10.76 & 9.11 & 10.69 & 6.40 & 9.65 & 9.58 & 13.04 \\
\hline$L M$ & 24.34 & 18.06 & 21.81 & 16.86 & 16.42 & 7.16 & 14.08 & 12.66 & 25.69 \\
\hline$L R$ & 602 & 494 & 349 & 275 & 322 & 89 & 258 & 212 & 635 \\
\hline
\end{tabular}

Note: $C A L L$ and PUT are the free call option value and free put option value given by Eqs. (5) and (6), respectively. $D(1), D(2), D(4), D(5)$ and $D(6)$ are the time-ofthe-day dummies, which have a value of 1 if the event count occurs between 10:09 and 11:00, between 11:00 and 12:00, between 13:00 and 14:00, between 14:00 and 15:00 and between 15:00 and 16:00, respectively. TOTALBID and TOTALASK are the average number of "live" limit buy and limit sell orders based on 12 fiveminute snapshots of the limit order book in the interval. $\alpha$ and Std error $(\alpha)$ are, respectively, the estimated overdispersion parameter $\alpha$ and its associated standard error of the negative binomial count regression. $L M$ is the LM (score) test statistic of the Poisson model against the Katz (1963) family of discrete distributions. $L R$ is the log-likelihood ratio that tests the Poisson model against the negative binomial model. WALD is the Wald test statistic based on the overdispersion parameter $\alpha$. The $z$-statistics of all estimators in Tables 3-6 are computed based on robust heteroskedastic consistent variance-covariance matrix. Hausman is the Hausman test statistic that the random effects model is correctly specified under the null. Robust $z$ statistics in parentheses. 
Table 4

Results of the negative binomial count regression of the number of limit sell order cancellations (LSC)

\begin{tabular}{|c|c|c|c|c|c|c|c|c|c|c|c|c|c|c|}
\hline & $N A B$ & $N C P$ & $W B C$ & $R I O$ & $C M L$ & $F B G$ & $W M C$ & $S G B$ & $W F T$ & $\mathrm{NMH}$ & $C M C$ & $G P T$ & $S R P$ & WES \\
\hline$D(1)$ & $\begin{array}{l}0.9233 \\
(15.92)\end{array}$ & $\begin{array}{l}1.1167 \\
(18.00)\end{array}$ & $\begin{array}{l}0.8752 \\
(14.80)\end{array}$ & $\begin{array}{l}0.8489 \\
(11.84)\end{array}$ & & & & & & & & & & \\
\hline$D(2)$ & $\begin{array}{l}0.6806 \\
(11.87)\end{array}$ & $\begin{array}{l}0.8144 \\
(12.45)\end{array}$ & $\begin{array}{l}0.6276 \\
(10.20)\end{array}$ & $\begin{array}{l}0.6912 \\
(10.61)\end{array}$ & $\begin{array}{c}0.4642 \\
(5.78)\end{array}$ & $\begin{array}{c}0.6427 \\
(8.75)\end{array}$ & $\begin{array}{c}0.6337 \\
(8.14)\end{array}$ & $\begin{array}{c}0.7272 \\
(7.56)\end{array}$ & & $\begin{array}{c}0.4049 \\
(3.86)\end{array}$ & $\begin{array}{c}0.6632 \\
(5.09)\end{array}$ & $\begin{array}{c}0.4918 \\
(4.23)\end{array}$ & $\begin{array}{c}0.4659 \\
(4.60)\end{array}$ & $\begin{array}{l}0.4050 \\
(3.52)\end{array}$ \\
\hline$D(4)$ & $\begin{array}{l}-0.9719 \\
(-12.40)\end{array}$ & $\begin{array}{c}-0.9472 \\
(-9.78)\end{array}$ & $\begin{array}{l}-0.9840 \\
(-12.57)\end{array}$ & $\begin{array}{l}-1.1301 \\
(-12.14)\end{array}$ & $\begin{array}{l}-0.7288 \\
(-6.75)\end{array}$ & $\begin{array}{c}-0.7853 \\
(-8.20)\end{array}$ & $\begin{array}{c}-0.9159 \\
(-8.28)\end{array}$ & $\begin{array}{l}-0.9078 \\
(-6.78)\end{array}$ & $\begin{array}{l}-1.2565 \\
(-7.71)\end{array}$ & $\begin{array}{l}-0.8441 \\
(-6.23)\end{array}$ & $\begin{array}{l}-1.3371 \\
(-5.95)\end{array}$ & $\begin{array}{c}-1.2497 \\
(-7.80)\end{array}$ & $\begin{array}{c}-1.0333 \\
(-7.34)\end{array}$ & $\begin{array}{l}-0.9447 \\
(-5.70)\end{array}$ \\
\hline$D(5)$ & & & & & & & & & & & & & & \\
\hline$D(6)$ & $\begin{array}{l}0.9900 \\
(14.71)\end{array}$ & $\begin{array}{l}1.1250 \\
(14.93)\end{array}$ & & $\begin{array}{l}1.0463 \\
(14.48)\end{array}$ & $\begin{array}{c}0.7753 \\
(9.47)\end{array}$ & & & $\begin{array}{l}0.9299 \\
(9.37)\end{array}$ & & & & & $\begin{array}{l}0.78 \\
(7.7\end{array}$ & $\begin{array}{l}0.7597 \\
(6.11)\end{array}$ \\
\hline TOTALBID & $\begin{array}{c}-0.0000 \\
(-0.19)\end{array}$ & $\begin{array}{c}0.0002 \\
(0.36)\end{array}$ & $\begin{array}{c}0.0006 \\
(3.96)\end{array}$ & $\begin{array}{l}-0.0016 \\
(-0.77)\end{array}$ & $\begin{array}{c}0.0001 \\
(0.59)\end{array}$ & $\begin{array}{l}-0.0007 \\
(-4.01)\end{array}$ & $\begin{array}{l}-0.0012 \\
(-3.95)\end{array}$ & $\begin{array}{c}-0.0013 \\
(-1.67)\end{array}$ & $\begin{array}{l}-0.0145 \\
(-3.56)\end{array}$ & & $\begin{array}{c}0.0026 \\
(0.55)\end{array}$ & & $\begin{array}{l}-0.0031 \\
(-3.29)\end{array}$ & \\
\hline TOTALASK & & $\begin{array}{c}0.0002 \\
(0.23)\end{array}$ & & & & & & & & & & & $\begin{array}{c}0.0034 \\
(2.61)\end{array}$ & $\begin{array}{l}0.0016 \\
(0.39)\end{array}$ \\
\hline$C A L L$ & $\begin{array}{c}0.6686 \\
(3.42)\end{array}$ & $\begin{array}{l}0.2820 \\
(0.84)\end{array}$ & $\begin{array}{l}0.9949 \\
(1.41)\end{array}$ & $\begin{array}{l}0.4621 \\
(3.98)\end{array}$ & $\begin{array}{c}-0.1664 \\
(0.19)\end{array}$ & $\begin{array}{l}1.3923 \\
(1.28)\end{array}$ & $\begin{array}{l}1.9357 \\
(4.03)\end{array}$ & $\begin{array}{l}2.9061 \\
(2.92)\end{array}$ & $\begin{array}{l}6.0556 \\
(1.33)\end{array}$ & $\begin{array}{l}5.5385 \\
(1.89)\end{array}$ & $\begin{array}{l}-0.4278 \\
(-0.40)\end{array}$ & $\begin{array}{l}4.2775 \\
(0.84)\end{array}$ & $\begin{array}{l}2.9412 \\
(2.52)\end{array}$ & $\begin{array}{l}0.6721 \\
(1.39)\end{array}$ \\
\hline$P U T$ & $\begin{array}{l}1.0148 \\
(2.77)\end{array}$ & $\begin{array}{l}1.0312 \\
(2.60)\end{array}$ & $\begin{array}{l}3.2520 \\
(4.58)\end{array}$ & $\begin{array}{c}0.9937 \\
(4.81)\end{array}$ & $\begin{array}{l}2.3452 \\
(2.52)\end{array}$ & $\begin{array}{l}3.5629 \\
(2.74)\end{array}$ & $\begin{array}{l}3.3953 \\
(5.00)\end{array}$ & $\begin{array}{l}3.2443 \\
(4.37)\end{array}$ & $\begin{array}{l}5.1502 \\
(1.71)\end{array}$ & $\begin{array}{l}9.2046 \\
(3.37)\end{array}$ & $\begin{array}{l}1.7405 \\
(1.47)\end{array}$ & $\begin{array}{l}-0.5087 \\
(-0.12)\end{array}$ & $\begin{array}{l}6.0532 \\
(4.22)\end{array}$ & $\begin{array}{l}2.2180 \\
(2.12)\end{array}$ \\
\hline Constant & $\begin{array}{l}1.5061 \\
(26.26)\end{array}$ & $\begin{array}{l}1.2395 \\
(17.18)\end{array}$ & $\begin{array}{l}1.2453 \\
(17.33)\end{array}$ & $\begin{array}{l}1.0477 \\
(10.33)\end{array}$ & $\begin{array}{l}0.9155 \\
(7.94)\end{array}$ & $\begin{array}{l}0.8140 \\
(9.67)\end{array}$ & $\begin{array}{l}1.2932 \\
(11.08)\end{array}$ & $\begin{array}{l}0.4908 \\
(2.95)\end{array}$ & $\begin{array}{l}0.1594 \\
(0.86)\end{array}$ & $\begin{array}{c}-0.0760 \\
(-0.41)\end{array}$ & $\begin{array}{c}-0.5637 \\
(-3.69)\end{array}$ & $\begin{array}{c}0.0058 \\
(0.04)\end{array}$ & $\begin{array}{c}0.3543 \\
(2.60)\end{array}$ & $\begin{array}{l}0.0746 \\
(0.54)\end{array}$ \\
\hline Log likelihood & -4065 & -3898 & -3723 & -3445 & -3515 & -3526 & -3643 & -2530 & -2290 & -2390 & -1859 & -2143 & -2582 & \\
\hline Pearson $R^{2}$ & 0.81 & 0.78 & 0.77 & 0.77 & 0.67 & 0.76 & 0.75 & 0.58 & 0.51 & 0.53 & 0.51 & 0.52 & 0.59 & 0.59 \\
\hline & 0.19 & 0.23 & 0.22 & 0.26 & 0.35 & 0.36 & 0.31 & 0.39 & 0.4 & 0.52 & 0.74 & 0.49 & 0.49 & 0.78 \\
\hline Std error $(\alpha)$ & 0.01 & 0.02 & 0.02 & 0.02 & 0.03 & 0.02 & 0.02 & 0.04 & 0.05 & 0.05 & 0.08 & 0.05 & 0.04 & 0.07 \\
\hline$W A L D$ & 15.27 & 13.67 & 13.38 & 14.08 & 13.63 & 16.21 & 13.23 & 9.28 & 8.89 & 10.70 & 9.82 & 9.56 & 11.61 & 10.43 \\
\hline$L M$ & 36.95 & 34.81 & 29.81 & 27.48 & 33.79 & 32.64 & 37.11 & 18.10 & 12.93 & 16.68 & 13.65 & 12.34 & 18.59 & 21.99 \\
\hline$L R$ & 1143 & 1033 & 847 & 791 & 868 & 1019 & 1049 & 331 & 198 & 309 & 228 & 210 & 378 & 434 \\
\hline
\end{tabular}




\begin{tabular}{|c|c|c|c|c|c|c|c|c|c|}
\hline & $T A H$ & $M B L$ & $A G L$ & $H V N$ & $P D P$ & $A F I$ & $S M E$ & $G M F$ & $M A Y$ \\
\hline \multirow[t]{2}{*}{$D(1)$} & 0.4662 & 0.3896 & 0.5237 & 0.5113 & 0.7414 & 0.2962 & 0.4389 & 0.8820 & 0.7333 \\
\hline & $(5.90)$ & $(3.56)$ & $(5.73)$ & $(4.01)$ & $(7.28)$ & $(1.67)$ & $(3.94)$ & $(9.35)$ & $(7.65)$ \\
\hline \multirow[t]{2}{*}{$D(2)$} & 0.4281 & 0.3957 & 0.3485 & 0.4227 & 0.4864 & 0.1786 & 0.4460 & 0.6069 & 0.5798 \\
\hline & $(5.22)$ & $(3.62)$ & $(3.86)$ & $(3.34)$ & (4.64) & $(0.96)$ & $(3.91)$ & $(6.54)$ & $(6.19)$ \\
\hline \multirow[t]{2}{*}{$D(4)$} & -1.0480 & -0.7848 & -0.7875 & -0.8774 & -0.8718 & -0.8815 & -0.8802 & -0.6998 & -0.8874 \\
\hline & $(-8.79)$ & $(-5.84)$ & $(-6.91)$ & $(-5.59)$ & $(-6.49)$ & $(-3.39)$ & $(-5.97)$ & $(-5.61)$ & $(-6.86)$ \\
\hline \multirow[t]{2}{*}{$D(5)$} & 0.6090 & 0.6618 & 0.4661 & 0.5872 & 0.5071 & 0.1920 & 0.3973 & 0.7432 & 0.6391 \\
\hline & $(7.85)$ & $(6.52)$ & $(5.14)$ & $(4.56)$ & $(4.89)$ & $(1.01)$ & $(3.44)$ & (7.94) & $(6.36)$ \\
\hline \multirow[t]{2}{*}{$D(6)$} & 0.8634 & 0.9392 & 0.7749 & 0.8870 & 0.7663 & 0.4443 & 0.5208 & 1.0010 & 0.8698 \\
\hline & (10.58) & $(8.85)$ & $(8.00)$ & $(7.10)$ & $(7.31)$ & $(2.19)$ & $(4.38)$ & (10.68) & $(8.70)$ \\
\hline \multirow[t]{2}{*}{ TOTALBID } & 0.0024 & 0.0066 & -0.0012 & -0.0014 & 0.0004 & -0.0065 & -0.0032 & 0.0008 & -0.0059 \\
\hline & $(2.74)$ & $(3.11)$ & $(-5.41)$ & $(-1.00)$ & $(1.18)$ & $(-3.08)$ & $(-1.36)$ & $(2.39)$ & $(-6.95)$ \\
\hline \multirow[t]{2}{*}{ TOTALASK } & 0.0002 & 0.0068 & 0.0017 & 0.0064 & -0.0009 & 0.0095 & -0.0030 & -0.0007 & -0.0000 \\
\hline & $(0.25)$ & (1.89) & $(2.34)$ & $(4.45)$ & $(-1.29)$ & $(2.46)$ & $(-2.69)$ & $(-1.23)$ & $(-0.06)$ \\
\hline \multirow[t]{2}{*}{$C A L L$} & 2.2145 & 0.8199 & 1.2741 & -1.0328 & 6.2365 & 6.9615 & 3.2048 & 15.1066 & 1.8102 \\
\hline & $(4.93)$ & $(2.15)$ & $(1.60)$ & $(-1.97)$ & $(1.92)$ & $(1.59)$ & $(2.09)$ & $(2.54)$ & $(0.90)$ \\
\hline \multirow[t]{2}{*}{$P U T$} & 2.2738 & 1.7326 & 2.5426 & -0.0056 & 12.0638 & 8.7186 & 6.7887 & 16.1940 & 4.2889 \\
\hline & $(3.98)$ & $(2.00)$ & (3.08) & $(-0.21)$ & $(2.99)$ & $(1.61)$ & $(3.71)$ & $(3.90)$ & (3.09) \\
\hline \multirow[t]{2}{*}{ Constant } & 0.5217 & -0.1442 & 0.6866 & -0.5647 & 0.2367 & -1.0727 & 0.1143 & 0.0185 & 0.7005 \\
\hline & $(6.53)$ & $(-0.97)$ & (7.18) & $(-5.37)$ & $(1.95)$ & $(-4.36)$ & $(0.79)$ & $(0.14)$ & $(5.30)$ \\
\hline Log likelihood & -3084 & -2727 & -2765 & -1947 & -2512 & -1172 & -2062 & -2528 & -2626 \\
\hline Pearson $R^{2}$ & 0.66 & 0.64 & 0.64 & 0.56 & 0.57 & 0.34 & 0.51 & 0.59 & 0.63 \\
\hline$\alpha$ & 0.37 & 0.6 & 0.43 & 0.84 & 0.46 & 1.13 & 0.56 & 0.43 & 0.5 \\
\hline Std error $(\alpha)$ & 0.03 & 0.05 & 0.04 & 0.08 & 0.04 & 0.20 & 0.06 & 0.04 & 0.04 \\
\hline$W A L D$ & 13.19 & 13.30 & 12.19 & 10.10 & 10.90 & 5.56 & 9.35 & 10.20 & 12.06 \\
\hline$L M$ & 23.82 & 20.52 & 25.18 & 16.52 & 18.24 & 10.57 & 12.72 & 15.98 & 20.78 \\
\hline$L R$ & 564 & 601 & 482 & 308 & 355 & 99 & 218 & 315 & 451 \\
\hline
\end{tabular}

Note: $C A L L$ and PUT are the free call option value and free put option value given by Eqs. (5) and (6), respectively. $D(1), D(2), D(4), D(5)$ and $D(6)$ are the time-ofthe-day dummies, which have a value of 1 if the event count occurs between 10:09 and 11:00, between 11:00 and 12:00, between 13:00 and 14:00, between 14:00 and 15:00 and between 15:00 and 16:00, respectively. TOTALBID and TOTALASK are the average number of "live" limit buy and limit sell orders based on 12 fiveminute snapshots of the limit order book in the interval. $\alpha$ and Std error $(\alpha)$ are, respectively, the estimated overdispersion parameter $\alpha$ and its associated standard error of the negative binomial count regression. $L M$ is the LM (score) test statistic of the Poisson model against the Katz (1963) family of discrete distributions. $L R$ is the log-likelihood ratio that tests the Poisson model against the negative binomial model. WALD is the Wald test statistic based on the overdispersion parameter $\alpha$. The $z$-statistics of all estimators in tables 3-6 are computed based on robust heteroskedastic consistent variance-covariance matrix. Hausman is the Hausman test statistic that the random effects model is correctly specified under the null. Robust $z$ statistics in parentheses. 
Table 5

Results of the negative binomial count regression of the number of limit buy order revisions (LBR)

\begin{tabular}{|c|c|c|c|c|c|c|c|c|c|c|c|c|c|c|}
\hline & $N A B$ & $N C P$ & $W B C$ & $R I O$ & $C M L$ & $F B G$ & $W M C$ & $S G B$ & $W F T$ & $N M H$ & $C M C$ & $G P T$ & $S R P$ & WES \\
\hline$D(1)$ & $\begin{array}{l}1.0721 \\
(18.37)\end{array}$ & $\begin{array}{l}1.1427 \\
(18.90)\end{array}$ & $\begin{array}{l}1.1192 \\
(18.23)\end{array}$ & $\begin{array}{l}1.2454 \\
(17.17)\end{array}$ & $\begin{array}{l}1.0492 \\
(17.26)\end{array}$ & $\begin{array}{l}1.0678 \\
(15.62)\end{array}$ & $\begin{array}{l}1.2007 \\
(16.47)\end{array}$ & $\begin{array}{l}1.1215 \\
(13.54)\end{array}$ & $\begin{array}{c}0.9473 \\
(8.13)\end{array}$ & $\begin{array}{l}0.9712 \\
(10.19)\end{array}$ & $\begin{array}{l}0.8531 \\
(6.53)\end{array}$ & $\begin{array}{c}0.9891 \\
(9.47)\end{array}$ & $\begin{array}{l}0.8871 \\
(10.77)\end{array}$ & $\begin{array}{c}0.6964 \\
(7.91)\end{array}$ \\
\hline$D(2)$ & $\begin{array}{l}0.6081 \\
(11.00)\end{array}$ & $\begin{array}{c}0.5986 \\
(9.45)\end{array}$ & $\begin{array}{c}0.5949 \\
(9.72)\end{array}$ & $\begin{array}{l}0.8120 \\
(11.14)\end{array}$ & $\begin{array}{c}0.5183 \\
(8.66)\end{array}$ & $\begin{array}{c}0.5019 \\
(6.95)\end{array}$ & $\begin{array}{c}0.5577 \\
(7.94)\end{array}$ & $\begin{array}{c}0.5688 \\
(6.98)\end{array}$ & $\begin{array}{c}0.4519 \\
(3.71)\end{array}$ & $\begin{array}{c}0.6456 \\
(6.71)\end{array}$ & $\begin{array}{c}0.7198 \\
(5.62)\end{array}$ & $\begin{array}{c}0.4530 \\
(4.10)\end{array}$ & $\begin{array}{c}0.4066 \\
(5.01)\end{array}$ & $\begin{array}{l}0.4155 \\
(4.73)\end{array}$ \\
\hline$D(4)$ & $\begin{array}{l}-0.6942 \\
(-10.57)\end{array}$ & $\begin{array}{l}-0.8315 \\
(-8.12)\end{array}$ & $\begin{array}{l}-0.7164 \\
(-8.84)\end{array}$ & $\begin{array}{l}-0.7118 \\
(-7.59)\end{array}$ & $\begin{array}{c}-0.3846 \\
(-5.87)\end{array}$ & $\begin{array}{l}-0.6925 \\
(-7.66)\end{array}$ & $\begin{array}{l}-1.1056 \\
(-10.58)\end{array}$ & $\begin{array}{l}-0.5820 \\
(-5.86)\end{array}$ & $\begin{array}{l}-0.8014 \\
(-3.69)\end{array}$ & $\begin{array}{l}-0.7090 \\
(-5.34)\end{array}$ & $\begin{array}{l}-0.6957 \\
(-4.15)\end{array}$ & $\begin{array}{l}-0.7028 \\
(-5.13)\end{array}$ & $\begin{array}{l}-0.7143 \\
(-7.55)\end{array}$ & $\begin{array}{l}-0.6991 \\
(-6.56)\end{array}$ \\
\hline$D(5)$ & $\begin{array}{l}0.6606 \\
(12.01)\end{array}$ & $\begin{array}{l}0.6744 \\
(10.74)\end{array}$ & $\begin{array}{c}0.5588 \\
(9.13)\end{array}$ & $\begin{array}{l}0.9584 \\
(13.12)\end{array}$ & $\begin{array}{c}0.3318 \\
(5.93)\end{array}$ & $\begin{array}{c}0.4559 \\
(6.52)\end{array}$ & $\begin{array}{c}0.5238 \\
(7.41)\end{array}$ & $\begin{array}{c}0.5520 \\
(6.87)\end{array}$ & $\begin{array}{c}0.5792 \\
(4.70)\end{array}$ & $\begin{array}{c}0.5569 \\
(5.75)\end{array}$ & $\begin{array}{c}0.7075 \\
(5.91)\end{array}$ & $\begin{array}{c}0.4404 \\
(3.85)\end{array}$ & $\begin{array}{c}0.5191 \\
(6.17)\end{array}$ & $\begin{array}{c}0.3517 \\
(3.90)\end{array}$ \\
\hline$D(6)$ & $\begin{array}{l}0.9174 \\
(15.41)\end{array}$ & $\begin{array}{l}1.0074 \\
(12.13)\end{array}$ & $\begin{array}{l}0.9332 \\
(14.37)\end{array}$ & $\begin{array}{l}1.3492 \\
(17.72)\end{array}$ & $\begin{array}{l}0.7024 \\
(11.54)\end{array}$ & $\begin{array}{l}0.9395 \\
(12.93)\end{array}$ & $\begin{array}{l}0.9789 \\
(12.24)\end{array}$ & $\begin{array}{l}1.0024 \\
(12.38)\end{array}$ & $\begin{array}{l}1.1490 \\
(9.68)\end{array}$ & $\begin{array}{l}1.0357 \\
(10.15)\end{array}$ & $\begin{array}{l}1.2645 \\
(10.13)\end{array}$ & $\begin{array}{l}1.0634 \\
(9.42)\end{array}$ & $\begin{array}{l}0.8927 \\
(10.63)\end{array}$ & $\begin{array}{l}0.7898 \\
(8.99)\end{array}$ \\
\hline TOTALBID & $\begin{array}{c}0.0007 \\
(5.67)\end{array}$ & $\begin{array}{c}0.0044 \\
(8.11)\end{array}$ & $\begin{array}{c}0.0016 \\
(9.23)\end{array}$ & $\begin{array}{c}0.0051 \\
(2.34)\end{array}$ & $\begin{array}{c}0.0004 \\
(4.53)\end{array}$ & $\begin{array}{l}0.0007 \\
(4.20)\end{array}$ & $\begin{array}{l}-0.0014 \\
(-4.41)\end{array}$ & $\begin{array}{c}0.0043 \\
(6.75)\end{array}$ & $\begin{array}{c}0.0139 \\
(2.74)\end{array}$ & $\begin{array}{c}0.0027 \\
(2.92)\end{array}$ & $\begin{array}{c}0.0181 \\
(4.63)\end{array}$ & $\begin{array}{c}0.0061 \\
(2.46)\end{array}$ & $\begin{array}{c}0.0015 \\
(1.92)\end{array}$ & $\begin{array}{l}0.0026 \\
(2.36)\end{array}$ \\
\hline TOTALASK & $\begin{array}{c}-0.0018 \\
(-4.28)\end{array}$ & $\begin{array}{l}-0.0047 \\
(-5.44)\end{array}$ & $\begin{array}{l}-0.0010 \\
(-5.29)\end{array}$ & $\begin{array}{c}-0.0073 \\
(-4.47)\end{array}$ & $\begin{array}{c}-0.0006 \\
(-1.68)\end{array}$ & $\begin{array}{l}-0.0014 \\
(-2.69)\end{array}$ & $\begin{array}{l}-0.0014 \\
(-3.60)\end{array}$ & $\begin{array}{l}-0.0017 \\
(-1.67)\end{array}$ & $\begin{array}{l}-0.0227 \\
(-3.31)\end{array}$ & $\begin{array}{l}-0.0041 \\
(-5.02)\end{array}$ & $\begin{array}{c}-0.0438 \\
(-7.18)\end{array}$ & $\begin{array}{c}-0.0033 \\
(-1.23)\end{array}$ & $\begin{array}{l}-0.0027 \\
(-2.60)\end{array}$ & $\begin{array}{c}-0.0204 \\
(-7.48)\end{array}$ \\
\hline$C A L L$ & $\begin{array}{l}1.4494 \\
(5.87)\end{array}$ & $\begin{array}{l}1.3092 \\
(2.54)\end{array}$ & $\begin{array}{l}4.0579 \\
(6.46)\end{array}$ & $\begin{array}{l}0.6088 \\
(4.02)\end{array}$ & $\begin{array}{l}3.8228 \\
(3.49)\end{array}$ & $\begin{array}{l}6.9070 \\
(3.68)\end{array}$ & $\begin{array}{l}3.4599 \\
(4.28)\end{array}$ & $\begin{array}{l}4.1621 \\
(4.47)\end{array}$ & $\begin{array}{c}22.1120 \\
(5.03)\end{array}$ & $\begin{array}{c}22.9836 \\
(6.32)\end{array}$ & $\begin{array}{l}3.7509 \\
(3.41)\end{array}$ & $\begin{array}{c}27.2879 \\
(4.91)\end{array}$ & $\begin{array}{l}7.7169 \\
(5.55)\end{array}$ & $\begin{array}{l}2.4841 \\
(5.46)\end{array}$ \\
\hline$P U T$ & $\begin{array}{l}0.2245 \\
(1.06)\end{array}$ & $\begin{array}{c}0.6669 \\
(1.25)\end{array}$ & $\begin{array}{l}1.3986 \\
(2.17)\end{array}$ & $\begin{array}{l}-0.0122 \\
(-0.06)\end{array}$ & $\begin{array}{c}-1.0854 \\
(-1.57)\end{array}$ & $\begin{array}{l}-1.7655 \\
(-1.19)\end{array}$ & $\begin{array}{l}1.7608 \\
(2.45)\end{array}$ & $\begin{array}{l}-0.0231 \\
(-0.03)\end{array}$ & $\begin{array}{l}2.9127 \\
(1.17)\end{array}$ & $\begin{array}{l}5.4508 \\
(1.68)\end{array}$ & $\begin{array}{c}-0.1012 \\
(-0.10)\end{array}$ & $\begin{array}{l}0.6363 \\
(0.13)\end{array}$ & $\begin{array}{c}-2.6873 \\
(-2.07)\end{array}$ & $\begin{array}{c}0.4953 \\
(1.64)\end{array}$ \\
\hline Constant & $\begin{array}{l}2.3627 \\
(44.49)\end{array}$ & $\begin{array}{l}1.6432 \\
(23.22)\end{array}$ & $\begin{array}{l}1.5397 \\
(22.19)\end{array}$ & $\begin{array}{l}1.3245 \\
(12.35)\end{array}$ & $\begin{array}{l}1.7270 \\
(20.37)\end{array}$ & $\begin{array}{l}1.4231 \\
(18.43)\end{array}$ & $\begin{array}{l}1.8817 \\
(17.50)\end{array}$ & $\begin{array}{c}0.5444 \\
(3.65)\end{array}$ & $\begin{array}{l}-0.0245 \\
(-0.10)\end{array}$ & $\begin{array}{l}0.5293 \\
(3.27)\end{array}$ & $\begin{array}{c}0.0964 \\
(0.68)\end{array}$ & $\begin{array}{c}-0.1835 \\
(-1.14)\end{array}$ & $\begin{array}{l}0.9507 \\
(8.92)\end{array}$ & $\begin{array}{r}1.1808 \\
(10.80)\end{array}$ \\
\hline Log likelihood & -5032 & -4265 & -4370 & -3935 & -4427 & -3906 & -4072 & -3413 & -2405 & -2737 & -2351 & -2329 & -3436 & -3306 \\
\hline Pearson $R^{2}$ & 0.91 & 0.83 & 0.87 & 0.85 & 0.83 & 0.81 & 0.87 & 0.77 & 0.53 & 0.69 & 0.68 & 0.64 & 0.76 & 0.75 \\
\hline$x$ & 0.24 & 0.27 & 0.26 & 0.33 & 0.24 & 0.32 & 0.4 & 0.37 & 0.61 & 0.49 & 0.88 & 0.59 & 0.41 & 0.51 \\
\hline Std error $(\alpha)$ & 0.01 & 0.02 & 0.02 & 0.02 & 0.02 & 0.02 & 0.02 & 0.02 & 0.07 & 0.04 & 0.07 & 0.05 & 0.03 & 0.03 \\
\hline$W A L D$ & 19.67 & 13.70 & 15.24 & 16.94 & 15.65 & 17.07 & 18.39 & 15.04 & 9.06 & 12.79 & 12.18 & 11.67 & 15.22 & 15.88 \\
\hline$L M$ & 92.45 & 57.86 & 62.43 & 49.15 & 54.88 & 46.69 & 68.07 & 35.19 & 25.98 & 24.69 & 26.20 & 17.13 & 35.19 & 34.65 \\
\hline$L R$ & 4033 & 1896 & 2216 & 1767 & 1919 & 1542 & 2628 & 1021 & 419 & 607 & 621 & 381 & 1068 & 1034 \\
\hline
\end{tabular}




\begin{tabular}{|c|c|c|c|c|c|c|c|c|c|}
\hline & $T A H$ & $M B L$ & $A G L$ & $H V N$ & $P D P$ & $A F I$ & $S M E$ & $G M F$ & $M A Y$ \\
\hline \multirow[t]{2}{*}{$D(1)$} & 0.8436 & 0.9274 & 0.9726 & 0.8199 & 0.7829 & 0.7931 & 0.7518 & 0.9341 & 0.7290 \\
\hline & (10.89) & $(10.41)$ & (14.11) & $(6.18)$ & $(8.23)$ & (7.39) & $(8.13)$ & $(8.34)$ & $(8.44)$ \\
\hline \multirow[t]{2}{*}{$D(2)$} & 0.5653 & 0.5918 & 0.4063 & 0.3138 & 0.3874 & 0.3624 & 0.4313 & 0.3707 & 0.5926 \\
\hline & (7.09) & $(6.34)$ & $(5.84)$ & $(2.40)$ & (3.94) & $(3.30)$ & $(4.89)$ & (3.28) & $(7.17)$ \\
\hline \multirow[t]{2}{*}{$D(4)$} & -0.6759 & -0.7623 & -0.4308 & -0.4418 & -0.6623 & -0.4269 & -0.6358 & -0.3200 & -0.7323 \\
\hline & $(-7.01)$ & $(-7.07)$ & $(-5.14)$ & $(-3.09)$ & $(-5.92)$ & $(-3.28)$ & $(-5.78)$ & $(-2.44)$ & $(-6.32)$ \\
\hline \multirow[t]{2}{*}{$D(5)$} & 0.5045 & 0.5178 & 0.3890 & 0.3600 & 0.2820 & 0.3963 & 0.3930 & 0.3871 & 0.4894 \\
\hline & $(6.57)$ & $(5.87)$ & $(5.22)$ & $(2.73)$ & $(2.70)$ & $(3.27)$ & $(4.42)$ & $(3.46)$ & $(5.58)$ \\
\hline \multirow[t]{2}{*}{$D(6)$} & 0.9813 & 0.9153 & 0.5872 & 0.7873 & 0.8871 & 0.8636 & 0.9069 & 0.9894 & 0.9654 \\
\hline & (12.61) & $(9.72)$ & $(7.87)$ & $(5.47)$ & $(9.05)$ & $(7.91)$ & $(9.75)$ & $(8.51)$ & $(10.42)$ \\
\hline \multirow[t]{2}{*}{ TOTALBID } & 0.0063 & 0.0135 & 0.0008 & 0.0068 & 0.0022 & 0.0035 & 0.0117 & 0.0031 & -0.0011 \\
\hline & $(7.48)$ & $(6.41)$ & $(4.68)$ & $(4.43)$ & $(7.37)$ & $(3.23)$ & $(6.33)$ & $(8.21)$ & $(1.39)$ \\
\hline \multirow[t]{2}{*}{ TOTALASK } & -0.0031 & -0.0171 & 0.0004 & -0.0055 & -0.0024 & -0.0115 & -0.0054 & -0.0013 & -0.0024 \\
\hline & $(-3.96)$ & $(-5.36)$ & $(0.62)$ & $(-3.06)$ & $(-3.64)$ & $(-5.04)$ & $(-5.42)$ & $(-1.90)$ & $(-3.64)$ \\
\hline \multirow[t]{2}{*}{$C A L L$} & 4.2503 & 1.9074 & 4.8113 & 2.6999 & 22.9903 & 8.3844 & 4.8211 & 33.4381 & 11.9833 \\
\hline & $(9.13)$ & $(3.32)$ & $(6.87)$ & $(1.97)$ & $(4.96)$ & $(1.81)$ & $(3.30)$ & $(5.36)$ & $(5.97)$ \\
\hline \multirow[t]{2}{*}{$P U T$} & -1.4303 & -0.2026 & -0.8364 & 0.1183 & 4.0208 & -0.4248 & 1.3348 & 3.7895 & 1.8159 \\
\hline & $(-2.33)$ & $(-0.64)$ & $(-1.15)$ & $(8.50)$ & $(1.50)$ & $(-0.11)$ & $(0.97)$ & $(0.59)$ & $(1.32)$ \\
\hline \multirow[t]{2}{*}{ Constant } & 0.9740 & 0.5069 & 1.1147 & 0.2222 & 0.6166 & 0.1990 & 0.3170 & -0.2044 & 0.9734 \\
\hline & (12.47) & $(3.76)$ & (14.81) & $(1.96)$ & $(5.15)$ & $(1.47)$ & $(2.47)$ & $(-1.30)$ & $(8.18)$ \\
\hline Log likelihood & -3900 & -3394 & -3681 & -2829 & -2998 & -2481 & -2953 & -2529 & -3204 \\
\hline Pearson $R^{2}$ & 0.82 & 0.79 & 0.80 & 0.75 & 0.73 & 0.61 & 0.72 & 0.65 & 0.74 \\
\hline$\alpha$ & 0.41 & 0.53 & 0.34 & 0.84 & 0.5 & 0.71 & 0.46 & 0.53 & 0.53 \\
\hline Std error $(\alpha)$ & 0.02 & 0.03 & 0.02 & 0.07 & 0.04 & 0.06 & 0.03 & 0.05 & 0.04 \\
\hline$W A L D$ & 17.18 & 15.91 & 16.02 & 12.66 & 13.03 & 12.60 & 13.40 & 10.40 & 15.09 \\
\hline$L M$ & 49.62 & 43.38 & 44.40 & 50.94 & 34.27 & 23.18 & 26.59 & 24.38 & 36.90 \\
\hline$L R$ & 1731 & 1447 & 1351 & 1234 & 876 & 516 & 690 & 493 & 1071 \\
\hline
\end{tabular}

Note: $C A L L$ and $P U T$ are the free call option value and free put option value given by Eqs. (5) and (6), respectively. $D(1), D(2), D(4), D(5)$ and $D(6)$ are the time-ofthe-day dummies, which have a value of 1 if the event count occurs between 10:09 and 11:00, between 11:00 and 12:00, between 13:00 and 14:00, between 14:00 and 15:00 and between 15:00 and 16:00, respectively. TOTALBID and TOTALASK are the average number of "live" limit buy and limit sell orders based on 12 fiveminute snapshots of the limit order book in the interval. $\alpha$ and Std error $(\alpha)$ are, respectively, the estimated overdispersion parameter $\alpha$ and its associated standard error of the negative binomial count regression. $L M$ is the LM (score) test statistic of the Poisson model against the Katz (1963) family of discrete distributions. $L R$ is the log-likelihood ratio that tests the Poisson model against the negative binomial model. WALD is the Wald test statistic based on the overdispersion parameter $\alpha$. The $z$-statistics of all estimators in tables 3-6 are computed based on robust heteroskedastic consistent variance-covariance matrix. Hausman is the Hausman test statistic that the random effects model is correctly specified under the null. Robust $z$ statistics in parentheses. 
Table 6

Results of the negative binomial count regression of the number of limit sell order revisions (LSR)

\begin{tabular}{|c|c|c|c|c|c|c|c|c|c|c|c|c|c|c|}
\hline & $N A B$ & $N C P$ & $W B C$ & $R I O$ & $C M L$ & $F B G$ & $W M C$ & $S G B$ & $W F T$ & $N M H$ & $C M C$ & $G P T$ & $S R P$ & WES \\
\hline$D(1)$ & $\begin{array}{l}1.2325 \\
(23.14)\end{array}$ & $\begin{array}{l}1.2083 \\
(19.67)\end{array}$ & $\begin{array}{l}1.1723 \\
(20.88)\end{array}$ & & $\begin{array}{l}1.1304 \\
(16.61)\end{array}$ & & $\begin{array}{l}1.1198 \\
(14.27)\end{array}$ & $\begin{array}{l}1.0393 \\
(14.29)\end{array}$ & & $\begin{array}{l}1.1386 \\
(13.37)\end{array}$ & $\begin{array}{c}0.9391 \\
(7.49)\end{array}$ & & $\begin{array}{l}0.9801 \\
(11.78)\end{array}$ & $\begin{array}{l}0.6214 \\
(6.53)\end{array}$ \\
\hline$D(2)$ & $\begin{array}{l}0.6799 \\
(12.67)\end{array}$ & $\begin{array}{l}0.6668 \\
(10.34)\end{array}$ & $\begin{array}{l}0.6900 \\
(12.11)\end{array}$ & $\begin{array}{l}0.8377 \\
(11.51)\end{array}$ & $\begin{array}{l}0.5227 \\
(7.29)\end{array}$ & $\begin{array}{c}0.7487 \\
(9.62)\end{array}$ & $\begin{array}{l}0.5767 \\
(7.34)\end{array}$ & $\begin{array}{c}0.5698 \\
(8.05)\end{array}$ & $\begin{array}{c}0.5324 \\
(4.98)\end{array}$ & $\begin{array}{c}0.5202 \\
(5.63)\end{array}$ & $\begin{array}{c}0.7026 \\
(5.56)\end{array}$ & $\begin{array}{l}0.4713 \\
(4.62)\end{array}$ & $\begin{array}{c}0.5766 \\
(6.94)\end{array}$ & $\begin{array}{l}0.3132 \\
(3.53)\end{array}$ \\
\hline$D(4)$ & $\begin{array}{l}-0.7156 \\
(-9.97)\end{array}$ & $\begin{array}{l}-0.9023 \\
(-7.83)\end{array}$ & $\begin{array}{c}-0.6780 \\
(-9.96)\end{array}$ & $\begin{array}{l}-1.0515 \\
(-11.05)\end{array}$ & $\begin{array}{l}-0.6814 \\
(-8.79)\end{array}$ & $\begin{array}{l}-0.6182 \\
(-6.51)\end{array}$ & $\begin{array}{l}-0.7714 \\
(-8.15)\end{array}$ & $\begin{array}{c}-0.7512 \\
(-8.51)\end{array}$ & $\begin{array}{l}-1.0293 \\
(-6.30)\end{array}$ & $\begin{array}{c}-0.5520 \\
(-5.94)\end{array}$ & $\begin{array}{l}-0.9778 \\
(-5.96)\end{array}$ & $\begin{array}{l}-0.9199 \\
(-6.45)\end{array}$ & $\begin{array}{l}-0.6274 \\
(-5.95)\end{array}$ & $\begin{array}{l}-0.6318 \\
(-6.58)\end{array}$ \\
\hline$D(5)$ & & & & & & & & & $\begin{array}{c}0.6992 \\
(6.66)\end{array}$ & & & & & $\begin{array}{l}0.4414 \\
(5.17)\end{array}$ \\
\hline$D(6)$ & & & & & & $\begin{array}{l}1.1526 \\
(14.07)\end{array}$ & & & & & & & & $\begin{array}{l}0.8281 \\
(9.44)\end{array}$ \\
\hline TOTALBID & $\begin{array}{c}-0.0002 \\
(-1.56)\end{array}$ & $\begin{array}{c}0.0004 \\
(0.72)\end{array}$ & $\begin{array}{c}0.0003 \\
(2.21)\end{array}$ & $\begin{array}{l}-0.0175 \\
(-7.70)\end{array}$ & $\begin{array}{c}-0.0005 \\
(5.11)\end{array}$ & $\begin{array}{c}-0.0001 \\
(-0.49)\end{array}$ & $\begin{array}{l}-0.0005 \\
(-1.60)\end{array}$ & $\begin{array}{c}0.0014 \\
(2.16)\end{array}$ & $\begin{array}{l}-0.0126 \\
(-3.25)\end{array}$ & $\begin{array}{c}0.0003 \\
(0.35)\end{array}$ & $\begin{array}{l}-0.0148 \\
(-3.32)\end{array}$ & $\begin{array}{c}-0.0109 \\
(-4.83)\end{array}$ & $\begin{array}{l}-0.0023 \\
(-2.95)\end{array}$ & $\begin{array}{l}-0.0044 \\
(-3.55)\end{array}$ \\
\hline TOTALASK & & $\begin{array}{l}0.0011 \\
(1.19)\end{array}$ & $\begin{array}{c}-0.0004 \\
(-2.27)\end{array}$ & $\begin{array}{c}0.0034 \\
(2.01)\end{array}$ & & $\begin{array}{c}-0.0004 \\
(-0.62)\end{array}$ & $\begin{array}{c}-0.0003 \\
(-0.76)\end{array}$ & $\begin{array}{c}-0.0002 \\
(-0.14)\end{array}$ & & & & & $\begin{array}{c}0.0021 \\
(2.14)\end{array}$ & $\begin{array}{l}0.0181 \\
(6.61)\end{array}$ \\
\hline$C A L L$ & $\begin{array}{c}0.6590 \\
(2.58)\end{array}$ & $\begin{array}{c}-0.4704 \\
(-1.21)\end{array}$ & $\begin{array}{l}0.3673 \\
(0.48)\end{array}$ & $\begin{array}{l}-0.0328 \\
(-0.25)\end{array}$ & $\begin{array}{c}-0.6625 \\
(0.85)\end{array}$ & $\begin{array}{l}-1.1161 \\
(-0.88)\end{array}$ & & & & & & $\begin{array}{l}1.8534 \\
(0.31)\end{array}$ & $\begin{array}{l}0.4449 \\
(0.42)\end{array}$ & $\begin{array}{l}0.5884 \\
(1.09)\end{array}$ \\
\hline PUT & $\begin{array}{l}1.9754 \\
(4.83)\end{array}$ & $\begin{array}{c}0.8021 \\
(1.65)\end{array}$ & $\begin{array}{c}4.3608 \\
(5.06)\end{array}$ & $\begin{array}{l}1.2150 \\
(5.53)\end{array}$ & $\begin{array}{l}3.9028 \\
(3.13)\end{array}$ & $\begin{array}{l}8.6119 \\
(5.25)\end{array}$ & $\begin{array}{l}5.7166 \\
(7.04)\end{array}$ & $\begin{array}{l}2.9942 \\
(3.61)\end{array}$ & $\begin{array}{c}10.3498 \\
(2.67)\end{array}$ & $\begin{array}{c}16.2087 \\
(6.59)\end{array}$ & $\begin{array}{l}3.9255 \\
(2.22)\end{array}$ & $\begin{array}{c}12.8542 \\
(2.98)\end{array}$ & $\begin{array}{l}8.9237 \\
(6.66)\end{array}$ & $\begin{array}{l}3.0298 \\
(2.53)\end{array}$ \\
\hline Constant & $\begin{array}{l}1.8226 \\
(31.94)\end{array}$ & $\begin{array}{l}1.4201 \\
(18.57)\end{array}$ & $\begin{array}{l}1.7309 \\
(25.66)\end{array}$ & $\begin{array}{l}1.6390 \\
(15.14)\end{array}$ & $\begin{array}{l}1.4982 \\
(15.64)\end{array}$ & $\begin{array}{l}1.0839 \\
(11.99)\end{array}$ & $\begin{array}{l}1.6187 \\
(12.91)\end{array}$ & $\begin{array}{l}0.8054 \\
(5.32)\end{array}$ & $\begin{array}{l}-0.2868 \\
(-1.55)\end{array}$ & $\begin{array}{l}0.3779 \\
(2.45)\end{array}$ & $\begin{array}{l}-0.4429 \\
(-3.24)\end{array}$ & $\begin{array}{l}0.1494 \\
(0.99)\end{array}$ & $\begin{array}{l}0.8387 \\
(7.70)\end{array}$ & $\begin{array}{l}0.5008 \\
(4.92)\end{array}$ \\
\hline Log likelihood & -4745 & -4201 & -4424 & -3860 & -3927 & -3760 & -4120 & -3341 & -2477 & -3090 & -2431 & -2328 & -3372 & -3212 \\
\hline Pearson $R^{2}$ & 0.90 & 0.80 & 0.87 & 0.86 & 0.82 & 0.83 & 0.84 & 0.72 & 0.59 & 0.72 & 0.67 & 0.58 & 0.74 & 0.76 \\
\hline & 0.23 & 0.31 & 0.25 & 0.33 & & 0.38 & 0.31 & 0.27 & 0.44 & 0.38 & 0.78 & & 0.38 & 0.54 \\
\hline Std error $(\alpha)$ & 0.01 & 0.02 & 0.01 & 0.02 & 0.02 & 0.02 & 0.02 & 0.02 & 0.04 & 0.03 & 0.06 & 0.04 & 0.03 & 0.03 \\
\hline$W A L D$ & 17.97 & 13.24 & 18.77 & 16.96 & 16.49 & 16.44 & 14.08 & 12.13 & 10.54 & 12.76 & 12.42 & 9.36 & 14.08 & 15.56 \\
\hline$L M$ & 76.94 & 56.69 & 59.20 & 49.67 & 43.72 & 45.25 & 61.89 & 26.38 & 16.78 & 26.89 & 26.85 & 14.46 & 33.07 & 38.82 \\
\hline$L R$ & 3146 & 1845 & 2308 & 1823 & 1462 & 1562 & 2085 & 669 & 315 & 672 & 641 & 253 & 926 & 1152 \\
\hline
\end{tabular}




\begin{tabular}{|c|c|c|c|c|c|c|c|c|c|}
\hline & $T A H$ & $M B L$ & $A G L$ & $H V N$ & $P D P$ & $A F I$ & $S M E$ & $G M F$ & $M A Y$ \\
\hline \multirow[t]{2}{*}{$D(1)$} & 0.7687 & 0.7756 & 0.9075 & 0.8649 & 1.0822 & 1.0491 & 0.9087 & 0.8261 & 1.1512 \\
\hline & $(10.22)$ & $(7.36)$ & (11.65) & (8.88) & (13.99) & $(9.63)$ & (10.87) & $(9.93)$ & (16.12) \\
\hline \multirow[t]{2}{*}{$D(2)$} & 0.5589 & 0.6379 & 0.4613 & 0.5554 & 0.3782 & 0.5320 & 0.5746 & 0.3412 & 0.5936 \\
\hline & $(7.41)$ & (6.04) & $(5.82)$ & $(5.74)$ & $(4.65)$ & $(4.48)$ & $(6.36)$ & (4.08) & $(8.13)$ \\
\hline \multirow[t]{2}{*}{$D(4)$} & -0.8517 & -0.9105 & -0.7546 & -0.6192 & -0.6077 & -0.5555 & -0.4064 & -0.3900 & -0.5690 \\
\hline & $(-8.94)$ & $(-7.22)$ & $(-7.62)$ & $(-5.20)$ & $(-6.32)$ & $(-3.93)$ & $(-4.04)$ & $(-4.39)$ & $(-6.52)$ \\
\hline \multirow[t]{2}{*}{$D(5)$} & 0.7065 & 0.8001 & 0.5095 & 0.5271 & 0.4644 & 0.5463 & 0.3895 & 0.3122 & 0.4624 \\
\hline & $(9.11)$ & $(8.01)$ & $(6.50)$ & $(5.26)$ & (5.69) & $(4.89)$ & $(4.21)$ & $(3.77)$ & $(6.06)$ \\
\hline \multirow[t]{2}{*}{$D(6)$} & 0.9877 & 1.1525 & 0.8150 & 1.0202 & 0.8405 & 0.9716 & 0.7297 & 0.7987 & 0.8721 \\
\hline & (12.83) & (11.58) & $(9.61)$ & (10.90) & (10.10) & $(8.74)$ & $(8.33)$ & $(9.41)$ & (10.87) \\
\hline \multirow[t]{2}{*}{ TOTALBID } & 0.0015 & -0.0050 & -0.0002 & -0.0033 & 0.0003 & -0.0031 & -0.0023 & 0.0016 & -0.0044 \\
\hline & $(1.79)$ & $(-2.20)$ & $(-0.79)$ & $(-2.96)$ & $(1.26)$ & $(-2.80)$ & $(-1.28)$ & $(5.30)$ & $(-7.10)$ \\
\hline \multirow[t]{2}{*}{ TOTALASK } & 0.0031 & 0.0183 & 0.0028 & 0.0061 & 0.0003 & 0.0011 & 0.0004 & 0.0013 & -0.0017 \\
\hline & $(4.03)$ & $(5.81)$ & $(4.55)$ & $(5.36)$ & $(0.47)$ & $(0.46)$ & $(0.49)$ & $(2.57)$ & $(-3.12)$ \\
\hline \multirow[t]{2}{*}{$C A L L$} & 0.3496 & 0.1393 & 1.2798 & -0.8893 & 4.2297 & -0.9716 & 0.7777 & 8.6532 & 0.2313 \\
\hline & $(0.54)$ & $(0.47)$ & $(2.03)$ & $(-1.81)$ & $(1.49)$ & $(-0.22)$ & $(0.72)$ & $(1.52)$ & $(0.16)$ \\
\hline \multirow[t]{2}{*}{ PUT } & 5.1201 & 3.4418 & 5.9875 & 0.0428 & 13.0733 & 17.2557 & 7.9101 & 17.0134 & 5.0590 \\
\hline & $(7.25)$ & $(4.21)$ & $(7.48)$ & $(0.64)$ & $(3.92)$ & $(4.15)$ & $(5.01)$ & $(2.92)$ & $(4.24)$ \\
\hline \multirow[t]{2}{*}{ Constant } & 0.8755 & 0.3125 & 0.9381 & 0.2797 & 0.6048 & 0.0029 & 0.4886 & -0.0040 & 1.4061 \\
\hline & (11.17) & $(2.13)$ & (10.83) & $(3.50)$ & $(6.16)$ & $(0.02)$ & $(4.22)$ & $(-0.04)$ & (14.06) \\
\hline Log likelihood & -3806 & -3109 & -3573 & -2877 & -3157 & -2422 & -2941 & -2859 & -3414 \\
\hline Pearson $R^{2}$ & 0.80 & 0.78 & 0.75 & 0.67 & 0.69 & 0.62 & 0.67 & 0.60 & 0.76 \\
\hline$\alpha$ & 0.39 & 0.56 & 0.36 & 0.62 & 0.33 & 0.67 & 0.46 & 0.32 & 0.33 \\
\hline Std error $(\alpha)$ & 0.02 & 0.04 & 0.02 & 0.05 & 0.03 & 0.06 & 0.04 & 0.03 & 0.02 \\
\hline$W A L D$ & 15.74 & 13.33 & 15.31 & 13.45 & 12.47 & 11.26 & 12.87 & 9.56 & 13.90 \\
\hline$L M$ & 49.42 & 42.36 & 38.28 & 29.78 & 24.51 & 22.42 & 23.68 & 18.59 & 29.53 \\
\hline$L R$ & 1612 & 1104 & 1292 & 757 & 598 & 483 & 600 & 366 & 835 \\
\hline
\end{tabular}

Note: $C A L L$ and $P U T$ are the free call option value and free put option value given by Eqs. (5) and (6), respectively. $D(1), D(2), D(4), D(5)$ and $D(6)$ are the time-ofthe-day dummies, which have a value of 1 if the event count occurs between 10:09 and 11:00, between 11:00 and 12:00, between 13:00 and 14:00, between 14:00 and 15:00 and between 15:00 and 16:00, respectively. TOTALBID and TOTALASK are the average number of "live" limit buy and limit sell orders based on 12 fiveminute snapshots of the limit order book in the interval. $\alpha$ and Std error $(\alpha)$ are, respectively, the estimated overdispersion parameter $\alpha$ and its associated standard error of the negative binomial count regression. $L M$ is the LM (score) test statistic of the Poisson model against the Katz (1963) family of discrete distributions. $L R$ is the log-likelihood ratio that tests the Poisson model against the negative binomial model. WALD is the Wald test statistic based on the overdispersion parameter $\alpha$. The $z$-statistics of all estimators in tables 3-6 are computed based on robust heteroskedastic consistent variance-covariance matrix. Hausman is the Hausman test statistic that the random effects model is correctly specified under the null. Robust $z$ statistics in parentheses. 
Table 7

Results of negative binomial count regression (with individual effects) of the number of limit buy order cancellations (LBC), limit sell order cancellations (LSC), limit buy o rder revisions (LBR) and limit sell order revisions (LSR)

\begin{tabular}{|c|c|c|c|c|c|c|c|c|c|c|c|c|c|c|c|c|}
\hline & $\begin{array}{l}(1) \\
L B C\end{array}$ & $\begin{array}{l}(2) \\
L S C\end{array}$ & $\begin{array}{l}(3) \\
L B R\end{array}$ & $\begin{array}{l}(4) \\
L S R\end{array}$ & $\begin{array}{c}(5) \\
L B C\end{array}$ & $\begin{array}{l}(6) \\
L S C\end{array}$ & $\begin{array}{c}(7) \\
L B R\end{array}$ & $\begin{array}{c}(8) \\
L S R\end{array}$ & $\begin{array}{c}(9) \\
L B C\end{array}$ & $\begin{array}{l}(10) \\
L S C\end{array}$ & $\begin{array}{l}(11) \\
L B R\end{array}$ & $\begin{array}{l}\text { (12) } \\
L S R\end{array}$ & $\begin{array}{l}(13) \\
L B C\end{array}$ & $\begin{array}{l}(14) \\
L S C\end{array}$ & $\begin{array}{l}(15) \\
L B R\end{array}$ & $\begin{array}{l}(16) \\
L S R\end{array}$ \\
\hline$D(1)$ & $\begin{array}{l}0.7061 \\
(18.84)\end{array}$ & $\begin{array}{l}0.7147 \\
(13.52)\end{array}$ & $\begin{array}{l}0.9587 \\
(27.01)\end{array}$ & $\begin{array}{l}1.0336 \\
(28.10)\end{array}$ & $\begin{array}{l}0.6925 \\
(18.73)\end{array}$ & $\begin{array}{l}0.7024 \\
(14.92)\end{array}$ & $\begin{array}{l}0.9540 \\
(27.38)\end{array}$ & $\begin{array}{l}1.0269 \\
(27.31)\end{array}$ & $\begin{array}{l}0.7015 \\
(18.70)\end{array}$ & $\begin{array}{l}0.7111 \\
(13.38)\end{array}$ & $\begin{array}{l}0.9544 \\
(26.96)\end{array}$ & $\begin{array}{l}1.0282 \\
(27.64)\end{array}$ & & & $\begin{array}{l}0.9782 \\
(25.48)\end{array}$ & $\begin{array}{l}1.0486 \\
(23.93)\end{array}$ \\
\hline$D(2)$ & $\begin{array}{l}0.5366 \\
(20.89)\end{array}$ & $\begin{array}{l}0.5450 \\
(17.49)\end{array}$ & $\begin{array}{l}0.5097 \\
(18.81)\end{array}$ & $\begin{array}{l}0.5618 \\
(19.12)\end{array}$ & $\begin{array}{l}0.5286 \\
(20.78)\end{array}$ & $\begin{array}{l}0.5388 \\
(19.04)\end{array}$ & $\begin{array}{l}0.5079 \\
(18.54)\end{array}$ & $\begin{array}{l}0.5597 \\
(19.11)\end{array}$ & $\begin{array}{l}0.5343 \\
(20.86)\end{array}$ & $\begin{array}{l}0.5435 \\
(17.52)\end{array}$ & $\begin{array}{l}0.5083 \\
(18.87)\end{array}$ & $\begin{array}{l}0.5606 \\
(19.13)\end{array}$ & $\begin{array}{l}0.5705 \\
(22.53)\end{array}$ & $\begin{array}{l}0.5627 \\
(16.73)\end{array}$ & $\begin{array}{l}0.5297 \\
(20.67)\end{array}$ & $\begin{array}{l}0.5788 \\
(19.98)\end{array}$ \\
\hline$D(4)$ & $\begin{array}{l}-0.8141 \\
(-15.73)\end{array}$ & $\begin{array}{l}-0.9641 \\
(-27.56)(\end{array}$ & $\begin{array}{l}-0.7035 \\
(-16.77)\end{array}$ & $\begin{array}{l}-0.7557 \\
(-21.37)\end{array}$ & $\begin{array}{l}-0.8175 \\
(-15.61)\end{array}$ & $\begin{array}{l}-0.9655 \\
(-27.46)\end{array}$ & $\begin{array}{l}-0.7039 \\
(-16.78)\end{array}$ & $\begin{array}{l}-0.7564 \\
(-21.42)\end{array}$ & $\begin{array}{l}-0.8158 \\
(-15.67)\end{array}$ & $\begin{array}{l}-0.9642 \\
(-27.53)\end{array}$ & $\begin{array}{l}-0.7040 \\
(-16.77)\end{array}$ & $\begin{array}{l}-0.7563 \\
(-21.49)\end{array}$ & $\begin{array}{l}-0.7602 \\
(-15.72)\end{array}$ & $\begin{array}{l}-0.9354 \\
(-29.05)\end{array}$ & $\begin{array}{l}-0.6683 \\
(-16.19)\end{array}$ & $\begin{array}{l}-0.7201 \\
(-21.34)\end{array}$ \\
\hline$D(5)$ & $\begin{array}{l}0.6123 \\
(21.83)\end{array}$ & $\begin{array}{l}0.6474 \\
(17.12)\end{array}$ & $\begin{array}{l}0.5025 \\
(13.53)\end{array}$ & $\begin{array}{l}0.5982 \\
(18.54)\end{array}$ & $\begin{array}{l}0.6063 \\
(21.18)\end{array}$ & $\begin{array}{l}0.6437 \\
(17.83)\end{array}$ & $\begin{array}{l}0.5008 \\
(13.31)\end{array}$ & $\begin{array}{l}0.5972 \\
(18.66)\end{array}$ & $\begin{array}{l}0.6105 \\
(21.85)\end{array}$ & $\begin{array}{c}0.6472 \\
(17.13)\end{array}$ & $\begin{array}{l}0.5013 \\
(13.47)\end{array}$ & $\begin{array}{l}0.5987 \\
(18.26)\end{array}$ & $\begin{array}{l}0.6350 \\
(21.72)\end{array}$ & $\begin{array}{l}0.6602 \\
(17.35)\end{array}$ & $\begin{array}{c}0.5098 \\
(14.55)\end{array}$ & $\begin{array}{l}0.6119 \\
(17.64)\end{array}$ \\
\hline$E N D$ & $\begin{array}{l}0.6808 \\
(10.24)\end{array}$ & $\begin{array}{l}0.7220 \\
(12.25)\end{array}$ & $\begin{array}{l}0.7546 \\
(11.61)\end{array}$ & $\begin{array}{l}0.7903 \\
(13.48)\end{array}$ & $\begin{array}{l}0.6605 \\
(10.26)\end{array}$ & $\begin{array}{l}0.7066 \\
(12.89)\end{array}$ & $\begin{array}{l}0.7481 \\
(11.45)\end{array}$ & $\begin{array}{l}0.7839 \\
(13.81)\end{array}$ & $\begin{array}{l}0.6752 \\
(10.52)\end{array}$ & $\begin{array}{l}0.7179 \\
(12.66)\end{array}$ & $\begin{array}{l}0.7495 \\
(11.67)\end{array}$ & $\begin{array}{l}0.7860 \\
(13.63)\end{array}$ & $\begin{array}{l}0.8948 \\
(26.29)\end{array}$ & $\begin{array}{l}0.9187 \\
(22.68)\end{array}$ & $\begin{array}{l}0.9258 \\
(20.48)\end{array}$ & $\begin{array}{l}0.9334 \\
(22.32)\end{array}$ \\
\hline TOTALBID & $\begin{array}{l}0.0016 \\
(2.22)\end{array}$ & $\begin{array}{l}0.0012 \\
(2.11)\end{array}$ & $\begin{array}{l}0.0026 \\
(3.63)\end{array}$ & $\begin{array}{l}0.0012 \\
(1.92)\end{array}$ & $\begin{array}{l}0.0015 \\
(2.01)\end{array}$ & $\begin{array}{l}0.0011 \\
(1.88)\end{array}$ & $\begin{array}{l}0.0025 \\
(3.45)\end{array}$ & $\begin{array}{l}0.0012 \\
(1.79)\end{array}$ & $\begin{array}{l}0.0015 \\
(2.13)\end{array}$ & $\begin{array}{l}0.0012 \\
(2.00)\end{array}$ & $\begin{array}{l}0.0025 \\
(3.50)\end{array}$ & $\begin{array}{l}0.0011 \\
(1.79)\end{array}$ & $\begin{array}{l}0.0004 \\
(1.40)\end{array}$ & $\begin{array}{l}0.0002 \\
(0.76)\end{array}$ & $\begin{array}{l}0.0016 \\
(3.55)\end{array}$ & $\begin{array}{l}0.0003 \\
(0.89)\end{array}$ \\
\hline TOTALASK & $\begin{array}{c}0.0025 \\
(1.97)\end{array}$ & $\begin{array}{c}0.0028 \\
(2.33)\end{array}$ & $\begin{array}{c}0.0007 \\
(0.57)\end{array}$ & $\begin{array}{l}0.0028 \\
(2.72)\end{array}$ & $\begin{array}{l}0.0016 \\
(1.14)\end{array}$ & $\begin{array}{c}0.0021 \\
(1.50)\end{array}$ & $\begin{array}{c}0.0004 \\
(0.29)\end{array}$ & $\begin{array}{c}0.0024 \\
(2.05)\end{array}$ & $\begin{array}{c}0.0021 \\
(1.58)\end{array}$ & $\begin{array}{c}0.0024 \\
(1.92)\end{array}$ & $\begin{array}{c}0.0003 \\
(0.25)\end{array}$ & $\begin{array}{l}0.0024 \\
(2.15)\end{array}$ & $\begin{array}{l}0.0021 \\
(2.28)\end{array}$ & $\begin{array}{l}0.0024 \\
(2.69)\end{array}$ & $\begin{array}{c}0.0001 \\
(0.15)\end{array}$ & $\begin{array}{c}0.0024 \\
(3.28)\end{array}$ \\
\hline$C A L L$ & $\begin{array}{l}5.3622 \\
(4.98)\end{array}$ & $\begin{array}{l}4.0702 \\
(4.23)\end{array}$ & $\begin{array}{l}6.4766 \\
(4.43)\end{array}$ & $\begin{array}{l}3.0866 \\
(3.31)\end{array}$ & $\begin{array}{l}5.6339 \\
(5.17)\end{array}$ & $\begin{array}{l}4.3001 \\
(4.45)\end{array}$ & $\begin{array}{l}6.5842 \\
(4.52)\end{array}$ & $\begin{array}{l}3.1959 \\
(3.52)\end{array}$ & $\begin{array}{l}5.4512 \\
(5.11)\end{array}$ & $\begin{array}{l}4.1492 \\
(4.38)\end{array}$ & $\begin{array}{l}6.5702 \\
(4.47)\end{array}$ & $\begin{array}{l}3.1655 \\
(3.41)\end{array}$ & $\begin{array}{c}2.0145 \\
(3.17)\end{array}$ & $\begin{array}{l}1.1390 \\
(2.55)\end{array}$ & $\begin{array}{l}3.4737 \\
(3.07)\end{array}$ & $\begin{array}{l}0.9031 \\
(1.95)\end{array}$ \\
\hline$P U T$ & $\begin{array}{l}4.4868 \\
(4.21)\end{array}$ & $\begin{array}{l}5.6413 \\
(4.90)\end{array}$ & $\begin{array}{l}3.8677 \\
(3.21)\end{array}$ & $\begin{array}{l}6.8057 \\
(5.37)\end{array}$ & $\begin{array}{l}4.7909 \\
(4.69)\end{array}$ & $\begin{array}{l}5.9114 \\
(5.30)\end{array}$ & $\begin{array}{l}3.9678 \\
(3.40)\end{array}$ & $\begin{array}{l}6.9539 \\
(5.77)\end{array}$ & $\begin{array}{l}4.5781 \\
(4.41)\end{array}$ & $\begin{array}{l}5.7284 \\
(5.09)\end{array}$ & $\begin{array}{l}3.9505 \\
(3.30)\end{array}$ & $\begin{array}{l}6.8939 \\
(5.45)\end{array}$ & $\begin{array}{l}0.7726 \\
(1.19)\end{array}$ & $\begin{array}{l}1.9117 \\
(2.46)\end{array}$ & $\begin{array}{l}0.7328 \\
(1.08)\end{array}$ & $\begin{array}{l}3.8723 \\
(3.61)\end{array}$ \\
\hline$Q S$ & $\begin{array}{l}- \\
-\end{array}$ & $\begin{array}{l}- \\
-\end{array}$ & $\begin{array}{l}- \\
-\end{array}$ & $\begin{array}{l}- \\
-\end{array}$ & $\begin{array}{l}-7.7227 \\
(-1.13)\end{array}$ & $\begin{array}{l}-6.6319 \\
(-0.94)\end{array}$ & $\begin{array}{l}-2.9027 \\
(-0.43)\end{array}$ & $\begin{array}{l}-3.3478 \\
(-0.57)\end{array}$ & $\begin{array}{l}- \\
-\end{array}$ & $\begin{array}{l}- \\
-\end{array}$ & $\begin{array}{l}- \\
-\end{array}$ & $\begin{array}{l}- \\
-\end{array}$ & $\begin{array}{l}- \\
-\end{array}$ & $\begin{array}{l}- \\
-\end{array}$ & $\begin{array}{l}- \\
-\end{array}$ & $\begin{array}{l}- \\
-\end{array}$ \\
\hline$E S$ & - & - & $\begin{array}{l}- \\
-\end{array}$ & - & $\begin{array}{l}- \\
-\end{array}$ & $\begin{array}{l}- \\
-\end{array}$ & $\begin{array}{l}- \\
-\end{array}$ & $\begin{array}{l}- \\
-\end{array}$ & $\begin{array}{l}-2.3803 \\
(-0.88)\end{array}$ & $\begin{array}{l}-2.2084 \\
(-0.73)\end{array}$ & $\begin{array}{l}-2.3345 \\
(-0.73)\end{array}$ & $\begin{array}{l}-2.3598 \\
(-0.91)\end{array}$ & $\begin{array}{l}- \\
-\end{array}$ & $\begin{array}{l}- \\
-\end{array}$ & $\begin{array}{l}- \\
-\end{array}$ & $\begin{array}{l}- \\
-\end{array}$ \\
\hline SIZE & $\begin{array}{l}- \\
-\end{array}$ & $\begin{array}{l}- \\
-\end{array}$ & $\begin{array}{l}- \\
-\end{array}$ & $\begin{array}{l}- \\
-\end{array}$ & $\begin{array}{l}- \\
-\end{array}$ & $\begin{array}{l}- \\
-\end{array}$ & $\begin{array}{l}- \\
-\end{array}$ & $\begin{array}{l}- \\
-\end{array}$ & $\begin{array}{l}- \\
-\end{array}$ & $\begin{array}{l}- \\
-\end{array}$ & $\begin{array}{l}- \\
-\end{array}$ & $\begin{array}{l}- \\
-\end{array}$ & $\begin{array}{l}0.6437 \\
(10.72)\end{array}$ & $\begin{array}{l}0.6430 \\
(10.92)\end{array}$ & $\begin{array}{c}0.5464 \\
(9.70)\end{array}$ & $\begin{array}{l}0.4885 \\
(8.60)\end{array}$ \\
\hline Constant & $\begin{array}{c}0.1719 \\
(0.80)\end{array}$ & $\begin{array}{c}0.1007 \\
(0.50)\end{array}$ & $\begin{array}{l}0.6084 \\
(3.43)\end{array}$ & $\begin{array}{l}0.5132 \\
(3.17)\end{array}$ & $\begin{array}{l}0.4595 \\
(1.27)\end{array}$ & $\begin{array}{c}0.3481 \\
(0.99)\end{array}$ & $\begin{array}{l}0.7188 \\
(2.11)\end{array}$ & $\begin{array}{l}0.6401 \\
(2.14)\end{array}$ & $\begin{array}{c}0.2860 \\
(1.12)\end{array}$ & $\begin{array}{c}0.2058 \\
(0.83)\end{array}$ & $\begin{array}{l}0.7202 \\
(2.92)\end{array}$ & $\begin{array}{c}0.6263 \\
(2.87)\end{array}$ & $\begin{array}{l}-14.1465 \\
(-10.05)\end{array}$ & $\begin{array}{l}-14.1935 \\
(-10.25)\end{array}$ & $\begin{array}{c}-11.4887 \\
(-8.93)\end{array}$ & $\begin{array}{c}-10.3037 \\
(-7.94)\end{array}$ \\
\hline
\end{tabular}




\begin{tabular}{|c|c|c|c|c|c|c|c|c|c|c|c|c|c|c|c|c|}
\hline Log likelihood & -72551 & -70286 & -85414 & -83925 & -72386 & -70171 & -85388 & -83886 & -72492 & -70239 & -85351 & -83850 & -68042 & -66063 & -81879 & -80784 \\
\hline Pearson $R^{2}$ & 0.64 & 0.65 & 0.78 & 0.76 & 0.64 & 0.65 & 0.78 & 0.77 & 0.64 & 0.65 & 0.78 & 0.77 & 0.62 & 0.63 & 0.78 & 0.77 \\
\hline$\alpha$ & 0.85 & 0.88 & 0.82 & 0.70 & 0.84 & 0.87 & 0.81 & 0.70 & 0.85 & 0.88 & 0.81 & 0.70 & 0.48 & 0.51 & 0.57 & 0.50 \\
\hline Std error $\alpha$ & 0.10 & 0.10 & 0.09 & 0.06 & 0.10 & 0.10 & 0.09 & 0.06 & 0.10 & 0.10 & 0.09 & 0.06 & 0.06 & 0.06 & 0.06 & 0.05 \\
\hline$W A L D$ & 8.54 & 8.51 & 9.47 & 11.08 & 8.66 & 8.61 & 9.32 & 11.02 & 8.43 & 8.41 & 9.44 & 11.11 & 7.47 & 8.00 & 8.79 & 10.50 \\
\hline$L M$ & 313.13 & 284.07 & 489.89 & 427.82 & 307.84 & 281.44 & 488.55 & 427.31 & 327.69 & 292.91 & 513.47 & 437.55 & 162.69 & 147.23 & 294.88 & 256.80 \\
\hline$L R$ & 50,188 & 46,094 & 91,213 & 76,178 & 49,877 & 45,958 & 91,172 & 76,213 & 52,892 & 48,063 & 95,749 & 78,118 & 19,958 & 18,383 & 48,129 & 40,729 \\
\hline
\end{tabular}

Note: $C A L L$ and PUT are the free call option value and free put option value given by Eqs. (5) and (6), respectively. $D(1), D(2), D(4), D(5)$ and $D(6)$ are the time-ofthe-day dummies, which have a value of 1 if the event count occurs between 10:09 and 11:00, between 11:00 and 12:00, between 13:00 and 14:00, between 14:00 and 15:00 and between 15:00 and 16:00, respectively. TOTALBID and TOTALASK are the average number of "live" limit buy and limit sell orders based on 12 fiveminute snapshots of the limit order book in the interval. $\alpha$ and Std error $(\alpha)$ are, respectively, the estimated overdispersion parameter $\alpha$ and its associated standard error of the negative binomial count regression. $L M$ is the LM (score) test statistic of the Poisson model against the Katz (1963) family of discrete distributions. $L R$ is the log-likelihood ratio that tests the Poisson model against the negative binomial model. WALD is the Wald test statistic based on the overdispersion parameter $\alpha$. The $z$-statistics of all estimators in Tables 3-6 are computed based on robust heteroskedastic consistent variance-covariance matrix. Hausman is the Hausman test statistic that the random effects model is correctly specified under the null. Robust $z$ statistics in parentheses. 
before the closure of the market become more aggressive. For example, intraday position takers (or day-traders) who need to liquidate positions acquired during the day will move from supplying liquidity to demanding liquidity. To avoid overnight market uncertainty and capital requirements, they may withdraw their queued orders and convert them to market orders if they realize that their orders are unlikely to be filled in the remaining time. Patient investors who have already established a position in the book and who wish to adjust their portfolios before the market closes will cancel and revise their limit orders. Patient traders with a deadline that exceeds one day may expose their limit orders overnight. They can revisit their orders the next trading day to accommodate any information generated by the European and North American markets.

Free option values (CALL and PUT) exhibit a similar U-shaped pattern, which corresponds to the U-shaped pattern of volatility documented by Wood, McInish and Ord (1985). A gradual increase in both average bid and ask depths (TOTALBID and TOTALASK) toward the last hours suggests that an increase in the rate of market order arrival attracts more limit order submissions, which more than offsets the increase in limit order cancellations.

This general time-of-the-day pattern indicates that the inclusion of time-of-the-day dummies is able to resolve, at least in part, the concern about spurious count regressions of order cancellation/revision counts on free option values since the dummy variables capture the seasonality on both side of the regression equation.

\section{Results}

Tables 3-6 present individual stocks' regression results of the negative binomial model of buy cancellation counts, sell cancellation counts, buy revision counts and sell revision counts. Tables 7 presents panel regression results of the negative binomial model with individual effects of limit order cancellation counts and limit order revision counts. Results of the Poisson count models are not reported, since I find strong evidence of overdispersion in both cancellation and revision count data.

I also report the Pearson $R^{2}$, developed by Cameron and Windmeijer (1996) based on the Pearson residuals. Pearson residuals are used because the residuals derived from the count model are heteroskedastic and asymmetric. The negative binomial models fit the count data reasonably well as the average Pearson $R^{2}$ for individual stocks are 0.62 and 0.75 , respectively, for cancellation counts and revision counts.

\subsection{Time-of-the-day pattern, quote depth and volatility}

All coefficients on the time-of-the-day dummies $(D(1), D(2), D(4), D(5)$ and $D(6))$ in all count models are statistically significant at the $1 \%$ level. They are positive except $D(4)$. This result provides direct statistical evidence of a U-shaped intraday pattern for the number of order cancellations and revisions. The result for order cancellations is in line with the findings of Biais, Hillion and Spatt (1995) and Ellul, Holden, Jain, and Jennings (2007), who report that cancellation activities tend to increase toward the end of trading hours. Traders adjust their orders more often in the morning to reflect the information that has arrived overnight and in the afternoon when their trading deadline approaches (since some orders are day orders). In the final minutes, patient traders close their deals by amending their limit orders to market orders. 
The sign of the estimated coefficients for quote depth (measured by the average number of 'live' orders in the bid-ask schedules) in all count models (both individual stock regression and panel regression) is broadly consistent with the existing literature. In particular, buyers tend to react more readily than sellers in responding to the change in the quote depth. For limit buy order cancellation and revision counts, Tables 3 and 5 show that between $70 \%$ and $90 \%$ of our 23 stocks coincide with the observation that buy cancellation and revision activities are more intense when the quote depth on the same side of the book is deep and less intense when the quote depth on the opposite side of the book is deep. For limit sell order cancellation and revision counts, less than $40 \%$ of our sample stocks have negative and significant estimated coefficients for TOTALBID and positive and significant estimated coefficients for TOTALASK. I also report the results when individual stock data is aggregated into a cross-section time-series panel. The panel regression results on order cancellation counts are mixed. The results for revision counts are a lot stronger, as the relation between limit order revision and quote depth is consistent with the existing empirical findings; the number of limit buy (sell) revisions increases when the bid (ask) depth increases and the number of limit buy (sell) revisions decreases when the ask (bid) depth increases. Traders often revise the order price to a marketable limit order (which is also considered as a type of order price revision in our sample) to ensure execution.

\subsection{FTO risk and non-execution risk}

Hypothesis 1a asserts that there is a link between FTO risk and the rate of limit order cancellations and revisions. It predicts that the estimated coefficients for PUT (CALL) are positive for limit buy (sell) order cancellations and revisions. An increase in buy (sell) cancellation and revision activities should be followed by an increase in the put (call) option value since patient traders monitor the information flow and stand ready to withdraw and revise their orders when they expect a sudden price adjustment.

For individual stock buy cancellation count regressions, results on FTO risk are mixed. While almost all 23 coefficients on PUT are positive, only about one-third of those are statistically significant. The lack of significance indicates that limit buyers are less capable of monitoring and promptly withdrawing their orders to avoid being picked off; when bad news arrives, sellers manoeuvre more quickly than buyers and pick off unadjusted orders. ${ }^{21}$ For sell cancellations, more than one-half of our sample stocks have a positive and significant relation between CALL and sell order cancellation counts. While results are improved when I aggregate individual stocks into a panel, the coefficient on PUT (CALL) for buy (sell) cancellation regression falls considerably and becomes insignificant once I control for firm size (see the panel regression results reported in columns 13-14 in Table 7). This result is not surprising because larger firms release more public information than smaller firms and hence the firm size variable captures most variations in cancellation counts that are attributed to the risk of being picked off.

\footnotetext{
${ }^{21}$ I check this interpretation by replacing PUT (and $C A L L$ ) with the number of sell trade (and buy trade) as proxies of picking off activities and I find a strong contemporaneous positive relation between the two. I also replace cancellation counts with the number of market order arrivals (I choose not to use trading volume because the coefficient would only capture the price impact of order size). I find that coefficients on PUT for market sell order count are positively and strongly significant across all stocks (except NCP), implying that picking off activities are strongly related to the free option values.
} 
As shown in Tables 5 and 6, the evidence on the link between FTO risk and the number of limit order revisions is weaker than the link between FTO risk and the number of limit order cancellations. Two stocks exhibit a negative and significant relation between limit buy order revision counts and free put option values, which is somewhat contrary to our prediction. Our panel regression results (Table 7) suggest that traders tend to cancel their orders rather than revise their orders. It appears that traders prefer canceling their orders when FTO risk is high because of the cost incurred in monitoring the revised orders.

Under Hypothesis 1b, I expect limit order traders to cancel and/or revise their limit buy (sell) orders when they expect an upward (downward) price change. The dual relation between non-execution risk and FTO risk highlighted earlier suggests that there should be a positive relation between the number of limit buy (sell) order cancellations/revisions and the free call (put) option values. I find strong evidence that traders respond swiftly when non-execution risk increases. For both order cancellation and order revision regressions, the call option values $(C A L L)$ for both buy order cancellation regressions and buy order revision regressions are positive and strongly significant. The results are similar for both sell order cancellation and sell order revision regressions, as coefficients for the put option value $(P U T)$ are positive and statistically significant. ${ }^{22}$ While the implications for nonexecution risk remain unchanged after aggregating the sample into a panel, the inclusion of the firm size variable reduces the non-execution cost coefficients on both buy and sell cancellation regressions by one-half. Again, I attribute this result to more public information releases for larger firms, which increase non-execution risk and thus weaken the relation between CALL (PUT) and buy (sell) cancellation counts.

Because the exact sequence of price changes in relation to order cancellations/revisions is unknown, I conduct a variety of robustness checks to ensure my results are consistent with different values of the free options. I use two-period and three-period mid-quote changes as proxies for option values and I find qualitatively similar results.

\subsection{Bid-ask spread and firm size}

I find weak evidence supporting the prediction that large stocks are closely monitored and, as a consequence, tend to have narrower bid-ask spreads. For all count regressions with individual effects, coefficients of the quoted spread variable $(Q S)$ are negative but insignificant. I find similar results when the effective spread variable $(E S)$ is used.

In line with the theoretical prediction, all estimated coefficients of firm size are positive and strongly significant. This result is consistent with the postulate that limit orders of large stocks are cancelled and revised more frequently than those of small stocks due to extensive press and analyst coverage. Since extensive press and analyst coverage implies a greater amount of public information releases, large firms attract more traders to engage in monitoring, thus leading to more frequent cancellations and revisions.

It can be argued that the inter-firm variation in the level of cancellation/revision activity is driven by differences in order placement activity rather than by the level of monitoring. Hence, as a robustness check, I scale the number of order buy (sell) cancellations and revisions by the average number of buy (sell) limit order submissions for each stock, and then regress the scaled values against the same set of independent variables. Since the

\footnotetext{
${ }^{22}$ I repeat the analysis on the number of limit orders that convert to market orders. The results are qualitatively similar (not reported).
} 
Table 8

Results of Tobit regression of the standardized number of limit buy order cancellations (LBC), limit sell order cancellations (LSC), limit buy order revisions (LBR) and limit sell order revisions (LSR)

\begin{tabular}{|c|c|c|c|c|c|c|c|c|c|c|c|c|c|c|c|c|}
\hline & $\begin{array}{c}(1) \\
L B C\end{array}$ & $\begin{array}{l}(2) \\
L S C\end{array}$ & $\begin{array}{c}(3) \\
L B R\end{array}$ & $\begin{array}{c}(4) \\
L S R\end{array}$ & $\begin{array}{c}(5) \\
L B C\end{array}$ & $\begin{array}{c}(6) \\
L S C\end{array}$ & $\begin{array}{c}(7) \\
L B R\end{array}$ & $\begin{array}{c}(8) \\
L S R\end{array}$ & $\begin{array}{c}(9) \\
L B C\end{array}$ & $\begin{array}{l}(10) \\
L S C\end{array}$ & $\begin{array}{l}(11) \\
L B R\end{array}$ & $\begin{array}{l}(12) \\
L S R\end{array}$ & $\begin{array}{l}(13) \\
L B C\end{array}$ & $\begin{array}{l}\text { (14) } \\
L S C\end{array}$ & $\begin{array}{l}(15) \\
L B R\end{array}$ & $\begin{array}{l}(16) \\
L S R\end{array}$ \\
\hline$D(1)$ & $\begin{array}{l}0.1832 \\
(29.77)\end{array}$ & $\begin{array}{l}0.2093 \\
(28.80)\end{array}$ & $\begin{array}{l}0.4139 \\
(45.57)\end{array}$ & $\begin{array}{l}0.5479 \\
(52.87)\end{array}$ & $\begin{array}{l}0.1836 \\
(29.85)\end{array}$ & $\begin{array}{l}0.2096 \\
(28.87)\end{array}$ & $\begin{array}{l}0.4156 \\
(45.98)\end{array}$ & $\begin{array}{l}0.5495 \\
(53.24)\end{array}$ & $\begin{array}{l}0.1838 \\
(29.96)\end{array}$ & $\begin{array}{l}0.2096 \\
(28.88)\end{array}$ & $\begin{array}{l}0.4144 \\
(45.74)\end{array}$ & $\begin{array}{l}0.5484 \\
(52.98)\end{array}$ & $\begin{array}{l}0.1853 \\
(30.18)\end{array}$ & $\begin{array}{l}0.2118 \\
(29.23)\end{array}$ & $\begin{array}{l}0.4144 \\
(45.60)\end{array}$ & $\begin{array}{l}0.5478 \\
(52.86)\end{array}$ \\
\hline$D(2)$ & $\begin{array}{l}0.1394 \\
(22.61)\end{array}$ & $\begin{array}{l}0.1588 \\
(21.83)\end{array}$ & $\begin{array}{l}0.1936 \\
(21.25)\end{array}$ & $\begin{array}{l}0.2545 \\
(24.49)\end{array}$ & $\begin{array}{l}0.1396 \\
(22.66)\end{array}$ & $\begin{array}{l}0.1590 \\
(21.87)\end{array}$ & $\begin{array}{l}0.1944 \\
(21.44)\end{array}$ & $\begin{array}{l}0.2553 \\
(24.66)\end{array}$ & $\begin{array}{l}0.1396 \\
(22.72)\end{array}$ & $\begin{array}{l}0.1589 \\
(21.87)\end{array}$ & $\begin{array}{l}0.1938 \\
(21.32)\end{array}$ & $\begin{array}{l}0.2547 \\
(24.54)\end{array}$ & $\begin{array}{l}0.1410 \\
(22.93)\end{array}$ & $\begin{array}{l}0.1607 \\
(22.15)\end{array}$ & $\begin{array}{l}0.1939 \\
(21.27)\end{array}$ & $\begin{array}{l}0.2545 \\
(24.48)\end{array}$ \\
\hline$D(4)$ & $\begin{array}{l}-0.1503 \\
(-23.11)\end{array}$ & $\begin{array}{l}-0.2184 \\
(-27.94)\end{array}$ & $\begin{array}{l}-0.1849 \\
(-19.58)\end{array}$ & $\begin{array}{l}-0.2268 \\
(-21.02)\end{array}$ & $\begin{array}{l}-0.1502 \\
(-23.11)\end{array}$ & $\begin{array}{l}-0.2184 \\
(-27.95)\end{array}$ & $\begin{array}{l}-0.1849 \\
(-19.67)\end{array}$ & $\begin{array}{l}-0.2266 \\
(-21.09)\end{array}$ & $\begin{array}{l}-0.1500 \\
(-23.14)\end{array}$ & $\begin{array}{l}-0.2183 \\
(-27.96)\end{array}$ & $\begin{array}{l}-0.1849 \\
(-19.62)\end{array}$ & $\begin{array}{l}-0.2267 \\
(-21.04)\end{array}$ & $\begin{array}{l}-0.1503 \\
(-23.14)\end{array}$ & $\begin{array}{l}-0.2193 \\
(-28.07)\end{array}$ & $\begin{array}{l}-0.1850 \\
(-19.57)\end{array}$ & $\begin{array}{l}-0.2268 \\
(-21.02)\end{array}$ \\
\hline$D(5)$ & $\begin{array}{l}0.1586 \\
(25.74)\end{array}$ & $\begin{array}{l}0.1939 \\
(26.70)\end{array}$ & $\begin{array}{l}0.1867 \\
(20.48)\end{array}$ & $\begin{array}{l}0.2794 \\
(26.89)\end{array}$ & $\begin{array}{l}0.1586 \\
(25.77)\end{array}$ & $\begin{array}{l}0.1939 \\
(26.72)\end{array}$ & $\begin{array}{l}0.1866 \\
(20.57)\end{array}$ & $\begin{array}{l}0.2793 \\
(26.98)\end{array}$ & $\begin{array}{l}0.1584 \\
(25.81)\end{array}$ & $\begin{array}{l}0.1938 \\
(26.72)\end{array}$ & $\begin{array}{l}0.1864 \\
(20.50)\end{array}$ & $\begin{array}{l}0.2792 \\
(26.90)\end{array}$ & $\begin{array}{l}0.1604 \\
(26.11)\end{array}$ & $\begin{array}{l}0.1962 \\
(27.09)\end{array}$ & $\begin{array}{l}0.1871 \\
(20.51)\end{array}$ & $\begin{array}{l}0.2793 \\
(26.88)\end{array}$ \\
\hline$E N D$ & $\begin{array}{l}0.2714 \\
(43.26)\end{array}$ & $\begin{array}{l}0.3274 \\
(44.26)\end{array}$ & $\begin{array}{l}0.4297 \\
(46.31)\end{array}$ & $\begin{array}{l}0.5386 \\
(50.76)\end{array}$ & $\begin{array}{l}0.2720 \\
(43.38)\end{array}$ & $\begin{array}{l}0.3280 \\
(44.36)\end{array}$ & $\begin{array}{l}0.4326 \\
(46.83)\end{array}$ & $\begin{array}{l}0.5414 \\
(51.22)\end{array}$ & $\begin{array}{l}0.2719 \\
(43.50)\end{array}$ & $\begin{array}{l}0.3277 \\
(44.36)\end{array}$ & $\begin{array}{l}0.4304 \\
(46.48)\end{array}$ & $\begin{array}{l}0.5391 \\
(50.88)\end{array}$ & $\begin{array}{l}0.2780 \\
(44.39)\end{array}$ & $\begin{array}{l}0.3358 \\
(45.46)\end{array}$ & $\begin{array}{l}0.4314 \\
(46.41)\end{array}$ & $\begin{array}{l}0.5383 \\
(50.70)\end{array}$ \\
\hline TOTALBID & $\begin{array}{c}0.0000 \\
(0.05)\end{array}$ & $\begin{array}{l}0.0001 \\
(4.47)\end{array}$ & $\begin{array}{l}0.0003 \\
(15.37)\end{array}$ & $\begin{array}{l}0.0000 \\
(0.14)\end{array}$ & $\begin{array}{c}0.0000 \\
(0.52)\end{array}$ & $\begin{array}{c}0.0001 \\
(4.86)\end{array}$ & $\begin{array}{l}0.0004 \\
(17.01)\end{array}$ & $\begin{array}{c}0.0000 \\
(1.61)\end{array}$ & $\begin{array}{l}0.0000 \\
(1.24)\end{array}$ & $\begin{array}{l}0.0001 \\
(5.07)\end{array}$ & $\begin{array}{l}0.0004 \\
(16.28)\end{array}$ & $\begin{array}{c}0.0000 \\
(0.86)\end{array}$ & $\begin{array}{l}-0.0001 \\
(-5.72)\end{array}$ & $\begin{array}{l}-0.0000 \\
(-1.83)\end{array}$ & $\begin{array}{l}0.0003 \\
(13.97)\end{array}$ & $\begin{array}{l}0.0000 \\
(0.25)\end{array}$ \\
\hline TOTALASK & $\begin{array}{c}0.0000 \\
(1.71)\end{array}$ & $\begin{array}{l}0.0000 \\
(0.15)\end{array}$ & $\begin{array}{l}-0.0010 \\
(-23.01)\end{array}$ & $\begin{array}{c}-0.0003 \\
(-5.77)\end{array}$ & $\begin{array}{l}0.0001 \\
(3.59)\end{array}$ & $\begin{array}{l}0.0001 \\
(1.95)\end{array}$ & $\begin{array}{l}-0.0006 \\
(-13.37)\end{array}$ & $\begin{array}{l}0.0001 \\
(1.24)\end{array}$ & $\begin{array}{c}0.0002 \\
(5.80)\end{array}$ & $\begin{array}{l}0.0001 \\
(2.32)\end{array}$ & $\begin{array}{l}-0.0008 \\
(-18.03)\end{array}$ & $\begin{array}{l}-0.0001 \\
(-2.85)\end{array}$ & $\begin{array}{l}0.0000 \\
(0.65)\end{array}$ & $\begin{array}{l}-0.0000 \\
(-1.01)\end{array}$ & $\begin{array}{l}-0.0010 \\
(-23.17)\end{array}$ & $\begin{array}{l}-0.0003 \\
(-5.75)\end{array}$ \\
\hline$C A L L$ & $\begin{array}{l}0.5740 \\
(16.37)\end{array}$ & $\begin{array}{c}0.3605 \\
(8.71)\end{array}$ & $\begin{array}{l}1.3128 \\
(25.16)\end{array}$ & $\begin{array}{c}-0.0279 \\
(-0.46)\end{array}$ & $\begin{array}{l}0.5595 \\
(15.91)\end{array}$ & $\begin{array}{l}0.3456 \\
(8.32)\end{array}$ & $\begin{array}{l}1.2379 \\
(23.75)\end{array}$ & $\begin{array}{c}-0.1034 \\
(-1.70)\end{array}$ & $\begin{array}{l}0.5553 \\
(15.88)\end{array}$ & $\begin{array}{c}0.3493 \\
(8.44)\end{array}$ & $\begin{array}{l}1.2907 \\
(24.77)\end{array}$ & $\begin{array}{l}-0.0463 \\
(-0.76)\end{array}$ & $\begin{array}{l}0.4487 \\
(12.70)\end{array}$ & $\begin{array}{l}0.2014 \\
(4.82)\end{array}$ & $\begin{array}{l}1.2817 \\
(24.28)\end{array}$ & $\begin{array}{c}-0.0235 \\
(-0.38)\end{array}$ \\
\hline PUT & $\begin{array}{c}0.0949 \\
(4.46)\end{array}$ & $\begin{array}{l}0.1807 \\
(7.22)\end{array}$ & $\begin{array}{l}0.2381 \\
(7.48)\end{array}$ & $\begin{array}{l}0.3909 \\
(10.73)\end{array}$ & $\begin{array}{c}0.0896 \\
(4.21)\end{array}$ & $\begin{array}{l}0.1752 \\
(7.00)\end{array}$ & $\begin{array}{c}0.2108 \\
(6.65)\end{array}$ & $\begin{array}{l}0.3627 \\
(9.98)\end{array}$ & $\begin{array}{l}0.0883 \\
(4.16)\end{array}$ & $\begin{array}{l}0.1766 \\
(7.07)\end{array}$ & $\begin{array}{l}0.2303 \\
(7.25)\end{array}$ & $\begin{array}{l}0.3842 \\
(10.55)\end{array}$ & $\begin{array}{l}0.0532 \\
(2.50)\end{array}$ & $\begin{array}{l}0.1285 \\
(5.14)\end{array}$ & $\begin{array}{l}0.2277 \\
(7.13)\end{array}$ & $\begin{array}{l}0.3923 \\
(10.73)\end{array}$ \\
\hline$Q S$ & $\begin{array}{l}- \\
-\end{array}$ & - & - & - & $\begin{array}{c}0.5205 \\
(4.58)\end{array}$ & $\begin{array}{c}0.5453 \\
(4.05)\end{array}$ & $\begin{array}{l}2.6837 \\
(16.16)\end{array}$ & $\begin{array}{l}2.7109 \\
(14.26)\end{array}$ & $\begin{array}{l}- \\
-\end{array}$ & $\begin{array}{l}- \\
-\end{array}$ & - & - & - & - & - & $\begin{array}{l}- \\
-\end{array}$ \\
\hline$E S$ & - & - & - & - & - & - & $\begin{array}{l}- \\
-\end{array}$ & $\begin{array}{l}- \\
-\end{array}$ & $\begin{array}{l}0.6266 \\
(11.43)\end{array}$ & $\begin{array}{c}0.3863 \\
(5.92)\end{array}$ & $\begin{array}{c}0.7430 \\
(9.20)\end{array}$ & $\begin{array}{c}0.6288 \\
(6.81)\end{array}$ & - & - & - & - \\
\hline SIZE & $\begin{array}{l}- \\
-\end{array}$ & $\begin{array}{l}- \\
-\end{array}$ & $\begin{array}{l}- \\
-\end{array}$ & $\begin{array}{l}- \\
-\end{array}$ & $\begin{array}{l}- \\
-\end{array}$ & $\begin{array}{l}- \\
-\end{array}$ & $\begin{array}{l}- \\
-\end{array}$ & $\begin{array}{l}- \\
-\end{array}$ & $\begin{array}{l}- \\
-\end{array}$ & $\begin{array}{l}- \\
-\end{array}$ & - & $\begin{array}{l}- \\
-\end{array}$ & $\begin{array}{l}0.0530 \\
(23.63)\end{array}$ & $\begin{array}{l}0.0670 \\
(25.20)\end{array}$ & $\begin{array}{l}0.0132 \\
(3.96)\end{array}$ & $\begin{array}{c}-0.0018 \\
(-0.46)\end{array}$ \\
\hline Constant & $\begin{array}{l}0.0555 \\
(10.99)\end{array}$ & $\begin{array}{l}0.0544 \\
(9.12)\end{array}$ & $\begin{array}{l}0.1760 \\
(23.80)\end{array}$ & $\begin{array}{l}0.1935 \\
(22.92)\end{array}$ & $\begin{array}{l}0.0352 \\
(5.23)\end{array}$ & $\begin{array}{l}0.0332 \\
(4.17)\end{array}$ & $\begin{array}{l}0.0707 \\
(7.17)\end{array}$ & $\begin{array}{l}0.0873 \\
(7.75)\end{array}$ & $\begin{array}{l}0.0238 \\
(4.12)\end{array}$ & $\begin{array}{l}0.0349 \\
(5.10)\end{array}$ & $\begin{array}{l}0.1381 \\
(16.31)\end{array}$ & $\begin{array}{l}0.1614 \\
(16.68)\end{array}$ & $\begin{array}{l}-1.1157 \\
(-22.36)\end{array}$ & $\begin{array}{l}-1.4249 \\
(-24.11)\end{array}$ & $\begin{array}{l}-0.1156 \\
(-1.56)\end{array}$ & $\begin{array}{l}0.2324 \\
(2.75)\end{array}$ \\
\hline Log likelihood & $-13,367$ & $-17,421$ & $-22,997$ & $-26,719$ & $-13,356$ & $-17,413$ & $-22,867$ & $-26,618$ & $-13,302$ & $-17,404$ & $-22,955$ & $-26,696$ & $-13,086$ & $-17,101$ & $-22,989$ & $-26,719$ \\
\hline
\end{tabular}

Note: $C A L L$ and PUT are the free call option value and free put option value given by Eqs. (5) and (6), respectively. $D(1), D(2), D(4), D(5)$ and $D(6)$ are the time-ofthe-day dummies, which have a value of 1 if the event count occurs between 10:09 and 11:00, between 11:00 and 12:00, between 13:00 and 14:00, between 14:00 and 15:00 and between 15:00 and 16:00, respectively. TOTALBID and TOTALASK are the average number of "live" limit buy and limit sell orders based on 12 fiveminute snapshots of the limit order book in the interval. $\alpha$ and Std error $(\alpha)$ are, respectively, the estimated overdispersion parameter $\alpha$ and its associated standard error of the negative binomial count regression. $L M$ is the LM (score) test statistic of the Poisson model against the Katz (1963) family of discrete distributions. $L R$ is the log-likelihood ratio that tests the Poisson model against the negative binomial model. WALD is the Wald test statistic based on the overdispersion parameter $\alpha$.

The $z$-statistics of all estimators in Tables 3-6 are computed based on robust heteroskedastic consistent variance-covariance matrix. Hausman is the Hausman test statistic that the random effects model is correctly specified under the null. $t$ Statistics in parentheses. 
distribution of the scaled value has a mass point at zero and is continuous for all values that are greater than zero, I use the TOBIT model to estimate the scaled number of cancellations/revisions. Results are reported in Table 8. With the exception of the number of scaled limit sell order revisions (column 16), all estimated coefficients of SIZE are positive and strongly significant and hence are consistent with the prediction. However, the estimated coefficients for all spread measures appear to contradict Hypothesis 2, as almost all spread coefficients are significantly positive. There are two plausible explanations for these results. First, the scaled number of limit order cancellations/revisions can be regarded as a proxy for the level of information risk, which is positively related to the size of the spread. Second, according to the model, patient traders always resubmit their orders at a favorable price if their orders expose them to high non-execution risk. But the scaling offset activities that relate to resubmission: that is, scaling implies that traders do not resubmit and narrow the spread, since a high level of limit order cancellations is partially offset by a high level of limit order submission. Hence, using the scaled number of limit order cancellations could potentially bias the results towards finding a positive relation.

I also check the robustness of the empirical results by controlling the indirect effect of stock price level on limit order cancellations because of its direct effect on the level of limit order submission activity. ${ }^{23}$ The presence of the price variable does not affect our main results (not reported).

\section{Concluding remarks}

This paper presents a simple model of limit order cancellation and revision and includes empirical analysis that highlights the interrelation between the bid-ask spread, monitoring costs and limit order submission risks. In the model, I show that limit order traders face the twin risks of being picked off and non-execution. To reduce these risks, traders can either (i) widen the spread or (ii) monitor the information flow closely and withdraw or revise their orders when the associated risks are high. But to implement the latter strategy, limit order traders must incur monitoring costs. The trade-off between the cost of monitoring and limit order submission risks leads to three hypotheses that examine links between limit order cancellation/revision activities, limit order submission risk, spread and firm size. The empirical results are consistent with traders' monitoring market events to reduce the FTO risk and the non-execution risk. If stocks are actively traded, an increase in the risk of being picked off or the risk of non-execution results in orders being more frequently canceled and revised.

By examining associations among monitoring news, the level of press coverage and analyst following, and firm size, I find that order cancellation/revision activity is positively and significantly related to firm size. I find weak support for our conjecture that stocks with wide bid-ask spreads have fewer cancellations and revisions.

Although the recent suggestion of the usage of "indexed orders" by Black (1995) and the formal analysis of Brown and Holden (2002) provide some insights into an alternative way to reduce limit order submission risks, these papers do not offer a satisfactory solution as

\footnotetext{
${ }^{23}$ For low-priced stocks, the per dollar cost of crossing the limit order spread is higher than for their counterparts. Therefore, more limit order submissions should be found in low-priced stocks, ceteris paribus. An increase in the number of queued limit orders in the book implies a higher rate of order cancellations/revisions, even though the aggregate level of monitoring is not necessarily higher.
} 
to which type of indexing is optimal. While they suggest the use of a stock index to index limit orders, they fail to recognize the lack of a time-series relation between the index and the value of the stock. For example, most small stocks do not co-move with the stock index in the very short term. Limit orders for stocks that are indexed to the stock index cannot eliminate free trading option risk and will thus require monitoring. A possible future research direction would be to seek alternative ways of indexing limit orders that will minimize free trading option risk and non-execution risk, but also reduce monitoring cost. Furthermore, the model developed in this paper assumes that order size does not affect the monitoring decision. In practice, institutional traders tend to monitor their orders more closely than retail investors, particularly when the size of their orders is sufficiently large. An interesting extension would be to endogenize order size. I would expect that the number of order cancellations and revisions weighted by order size is positively related to the free option values. If this postulate is true, then it may be useful to re-test the first hypothesis, using the ratio of the number of large limit order cancellations to the number of small limit order cancellations as the dependent variable.

\section{Appendix A}

\section{A.1. Proof of Proposition 1}

Since $\sigma$ and $\alpha$ are both positively related to the FTO cost and the non-execution cost, to prove this proposition, it would be sufficient to show that:

$$
\frac{\partial \lambda_{s}}{\partial \sigma}>0, \quad \frac{\partial \lambda_{b}}{\partial \sigma}>0, \quad \frac{\partial \lambda_{s}}{\partial \alpha}>0, \quad \frac{\partial \lambda_{b}}{\partial \alpha}>0
$$

Differentiating $\lambda_{m}$ with respect to $\alpha$ and $\sigma$ using Eq. (4) yields

$$
\begin{aligned}
& \frac{\partial \lambda_{s}}{\partial \sigma}=\frac{\partial \lambda_{b}}{\partial \sigma}=\frac{\alpha}{2 c}\left[1+\frac{10 \alpha^{2} \sigma}{(1-\alpha) \beta c}\right]^{-1 / 2}>0, \\
& \frac{\partial \lambda_{s}}{\partial \alpha}=\frac{\partial \lambda_{b}}{\partial \alpha}=-\frac{\beta}{10 \alpha^{2}}\left[1+\frac{10 \alpha^{2}}{(1-\alpha) \beta c} \sigma\right]^{1 / 2}+\frac{(2-\alpha) \sigma}{2(1-\alpha) c}\left[1+\frac{10 \alpha^{2}}{(1-\alpha) \beta c} \sigma\right]^{-1 / 2}+\frac{\beta}{10 \alpha^{2}}>0
\end{aligned}
$$

iff

$$
c>c^{\prime \prime} \equiv \frac{5 \alpha^{4}(1-\alpha) \sigma}{2 \beta[1-\alpha(1-\alpha)]} .
$$

Since $\lambda_{s}^{*}=\lambda_{b}^{*}=\lambda_{n}^{*}$ and $\sum \lambda_{m} \leqslant 1, \lambda_{m}^{*} \leqslant \frac{1}{3}$. It implies that

$$
c \geqslant c^{\prime} \equiv\left[\frac{9 \alpha(1-\alpha) \beta}{6(1-\alpha) \beta+10 \alpha}\right] \sigma .
$$

The sufficient condition for $\partial \lambda_{s} / \partial \alpha>0$ and $\partial \lambda_{b} / \partial \alpha>0$ is $c^{\prime}>c^{\prime \prime}$, which occurs when

$$
\beta>\frac{5 \alpha^{2}}{3[1-\alpha(1-\alpha)]} .
$$




\section{References}

Angel J., 1994. Limit versus market orders. Working paper, Georgetown University.

Bhushan, R., 1989. Firm characteristics and analyst following. Journal of Accounting and Economics 11, $255-274$.

Berkman, H., 1996. Large option trades, market makers and limit orders. Review of Financial Studies 9, 977-1002.

Biais, B., Hillion, P., Spatt, C., 1995. An empirical analysis of the limit order book and order flow in the Paris Bourse. Journal of Finance 50, 1655-1689.

Black, F., 1995. Equilibrium exchanges. Financial Analysts Journal 51, 23-29.

Brockman, P., Chung, D.Y., 2000. Informed and uninformed trading in an electronic, order-driven environment. The Financial Review 35, 125-146.

Brown, D., Holden, C.W., 2002. Adjustable limit orders. Working paper, Indiana University.

Cameron, A.C., Trivedi, P.K., 1986. Econometric models based on count data: comparisons and applications of some estimators and tests. Journal of Applied Econometrics 1, $29-53$.

Cameron, A.C., Trivedi, P.K., 1998. Regression Analysis of Count Data. Cambridge University Press, Cambridge.

Cameron, A.C., Windmeijer, F.A.G., 1996. R-Squared measures for count data regression models with applications to health care utilization. Journal of Business and Economic Statistics 14, 209-220.

Copeland, T.E., Galai, D., 1983. Information effects on the bid-ask spread. Journal of Finance 38, $1457-1469$.

Coppejans, M., Domowitz, I., 2002. Screen information, trader activity, and bid-ask spreads in a limit order market. Working paper, Pennsylvania State University.

Cordella, T., Foucault, T., 1999. Minimum price variations, time priority and quote dynamics. Journal of Financial Intermediation 8, 141-173.

Corin, S.A., Lipson, M.L., 2000. Order flow and liquidity around NYSE trading halts. Journal of Finance 55, 1771-1801.

Easley, D., Kiefer, N.M., O’Hara, M., Paperman, J.B., 1996. Liquidity, information, and infrequently traded stocks. Journal of Finance 51, 1405-1436.

Economides, N., Schwartz, R.A., 1995. Equity trading practices and market structure: assessing asset managers' demand for immediacy. Financial Markets, Institutions and Instruments 4, 1-46.

Ellul, A., Holden, C.W., Jain, P., Jennings, R.H., 2007. Order dynamics: recent evidence from the NYSE Journal of Empirical Finance 14, 636-661.

Foucault, T., 1999. Order flow composition and trading costs in a dynamic limit order market. Journal of Financial Market 2, 99-134.

Foucault, T., Röell, R., Sandås, P., 2003. Market making with costly monitoring: an analysis of the SOES controversy. Review of Financial Studies 16, 345-384.

Freeman, R.N., 1987. The association between accounting earnings and security returns for large and small firms. Journal of Accounting and Economics 9, 195-228.

Gadarowski, C., 2002. Financial press coverage and expected stock returns. Working paper, Cornell University.

Glosten, L., 1994. Is the electronic open limit order book inevitable? Journal of Finance 49, 1127-1161.

Goettler, R.L., Parlour, C.A., Rajan, U., 2005. Equilibrium in a dynamic limit order market. Journal of Finance 60, 2149-2192.

Greenwood, M., Yule, G.U., 1920. An inquiry into the nature of frequency distributions. Journal of the Royal Statistical Society 83, 255-279.

Griffiths, M.D., Smith, B.F., Turnbull, D.A.S., White, R.W., 2000. The costs and determinants of order aggressiveness. Journal of Financial Economics 56, 68-88.

Handa, P., Schwartz, R., 1996. Limit order trading. Journal of Finance 51, 1835-1861.

Harris, L., 1998. Optimal dynamic order submission strategies in some stylized trading problems. Financial Markets, Institutions and Instruments 7, 1-76.

Harris, L., 2003. Trading and Exchanges. Oxford University Press, New York.

Hasbrouck, J., Saar, G., 2002. Limit orders and volatility in a hybrid markets: the Island ECN. Working paper, New York University.

Hong, H., Lim, T., Stein, J., 2000. Bad news travel slowly: size, analyst coverage and the profitability of momentum strategies. Journal of Finance 55, 265-295.

Katz, L., 1963. Unified treatment of a broad class of discrete probability distribution. In: Patil, G.P. (Ed.), Proceedigs of the International Symposium on Discrete Distribution. Statistical Publishing, Calcutta. 
Liu, W.-M,. Sawyer, K.R., 2003. How free are free trading options? Pacific-Basin Finance Journal 11, 573-591. Parlour, C., 1998. Price dynamics in limit order markets. Review of Financial Studies 11, 789-816.

Ranaldo, A., 2004. Order aggressiveness in limit order markets. Journal of Financial Markets 7, 53-74.

Rock, S., Sedo, S., Willenborg, M., 2001. Analyst following and count-data econometrics. Journal of Accounting and Economics 30, 351-373.

Sandas, P., 2001. Adverse selection and competitive market making: empirical evidence form a limit order market. Review of Financial Studies 14, 705-734.

Stoll, H., 1992. Principles of trading market structure. Journal of Finance Services Research 6, 75-107.

Stoll, H., 2003. Market microstructure. In: Constantinides, G.M., Harris, M., Stulz, R.M. (Eds.), Handbook of the Economics of Finance, vol. 1A. Elsevier, Amsterdam, p. 2003.

Winkelmann, R., 1997. Econometric Analysis of Count Data. Springer, Berlin.

Wood, R.A., McInish, T.H., Ord, J.K., 1985. An investigation of transaction data for NYSE tocks. Journal of Finance 40, 723-739.

Yeo, W., 2005. Cancellation of limit orders. Working paper, National University of Singapore. 